\title{
التحرز من السفسطة \\ قراءة في تلخيص السفسطة لابن رشد عن أرسطو
}

\section{د. أحمد ميلاد حيدر}

جامعة مصراتة - كلية الآداب

\section{مقدمة:}

يتناول هذا البحث عرضاً من كتاب السفسطة الذي ألفه أرسطو، ووضعه ضمن كتبه المنطقية التي جمعها ثلة من تلاميذه بعد وفاته، وأطلقوا عليه اسم الأرغانون (Organon) التي تعني حسب اللسان اليوناني: الآلة أو الأداة التي تقوم العقل وتسدد الإنسان نحو طريق الصواب

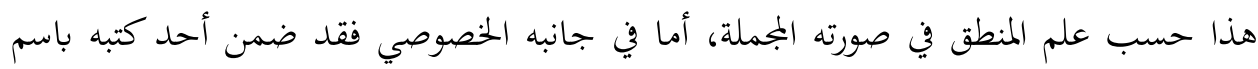
السفسطة Sophist، وذلك بسبب اعتماد الخنل في مسالك موضوعات المنطق، خاصة في متعلقات الاستدلال، ومنطق البرهان، والقياس وأنواع وقوانينه، وهذا ما يعني أن السوفسطائين، كانوا يعتمدون المغالطات والضلالات بغية الغلية في مجادلاقم ومحاوراتم، وإفحام الخصم والفوز عليه بشتى الطرق، أهمها التلاعب بالألفاظ والتشدق بها، وعرض الحجج الواهية المستندة على

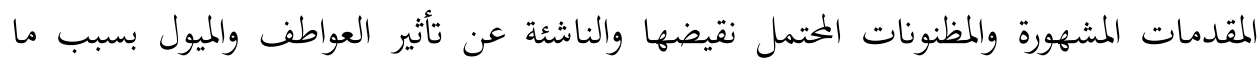
يمتلك هؤلاء من قدرة كلامية في أسلوب خطابي وقوة مجادلة ومحاورة، لذا حذرنا أرسطو من تجنب خداعهم والتحرز من تضليل مغالطاقم. وذلك بعد أن شرح منهجهم وأبان فيه عن

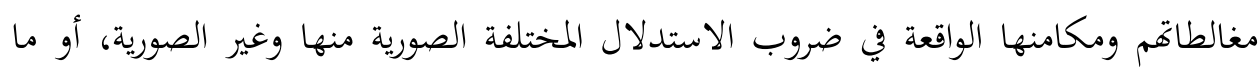
هو كائن بواسطة البراهين الزائفة القائمة على المتقابلات بين القضايا إلى جانب الخطابة ذات الأسلوب البلاغي، والمهم عند هذه الطائفة الغلبة والفوز بالمضلّلات لا بالحقائق. وقبل الولوج في عرض الموضوع، كان ولا بد أن أنداند أحدد الآتي: أ. مشكلة الدراسة: تبلورت هذه المشكلة في الصعوبة التي اعترضت الباحث من من ولئ

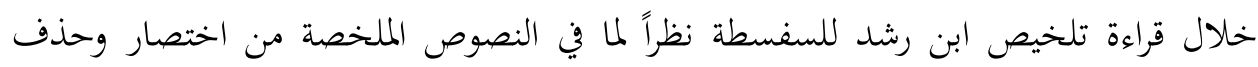


واقتضاب العبارة وسرعة اقتناص المعنى وتوظيفه في التراكيب والجمل. إلى جانب أن الملخصِّ في ملحَّصة يسعى جاداً إلى ما تمكن أن يمققه من مجمل حاصله وإلى ما يؤول إليه النص إبمالاًا.

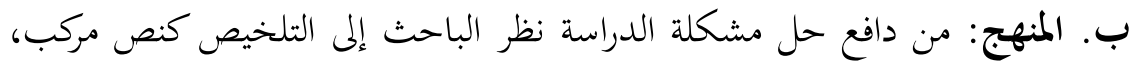

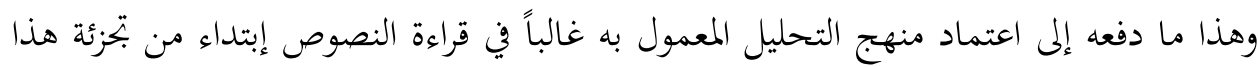

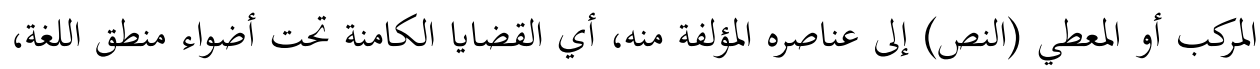

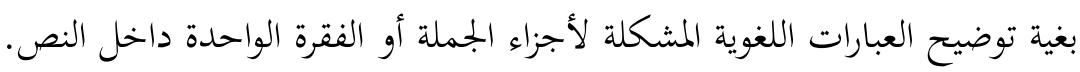

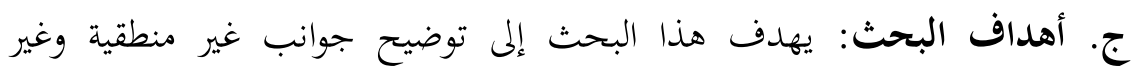

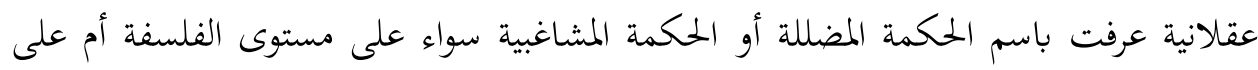
مستوى المنطق، التي اشتهر بها السوفسطائيون فتعمدوا المغالطات وشكوا في العقل وارتابوا في الماني

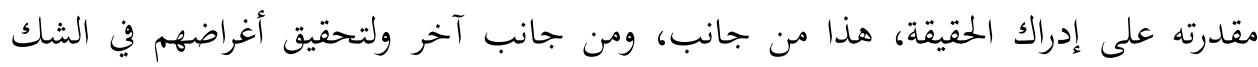

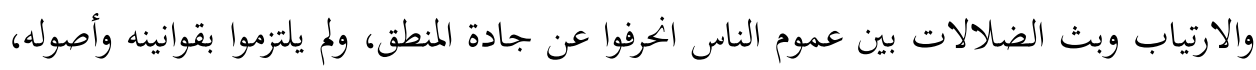

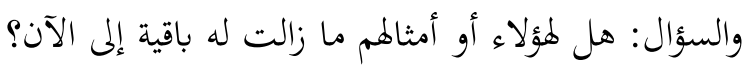

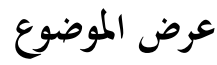

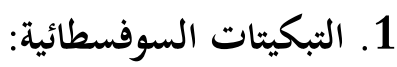

يطلق أرسطو والمناطقة اسم التبكيتات (1) على دحض الأدلة بقوة البرهان والغلبة والفوز

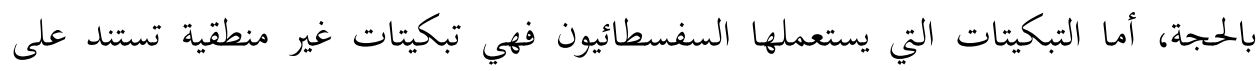
الأدلة الضعيفة والقياسات العقيمة، ومن هنا ابته هؤلاء إلى الغلبة والفوز بأساليب الملادة

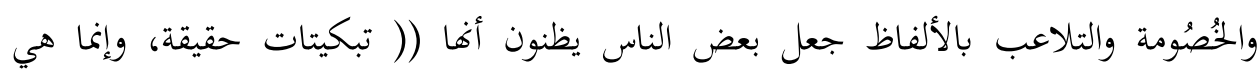
مضلات () (2) بغية المخادعة وإخفاء الحقيقة.

1- جاء في لسان العرب، لابن منظور في مادة (ب، ك، ت) بكت يبكته بكته بكتاً، بحتّه: ضربه بالسيف

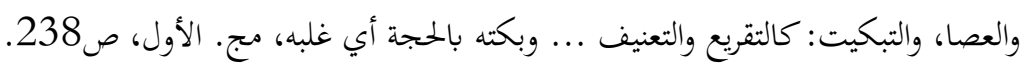

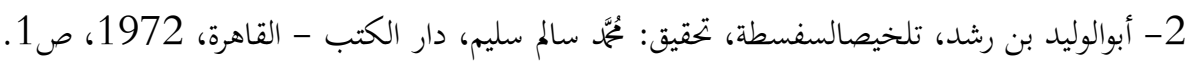


ما هو حقيقي صادق، وما هو زائف باطل، ثنائيان لا ينفك وجودهما في سائر الأشياء

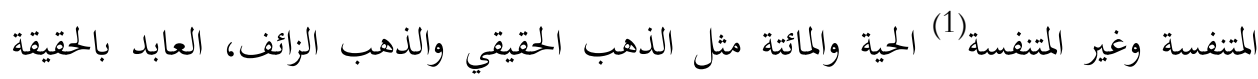

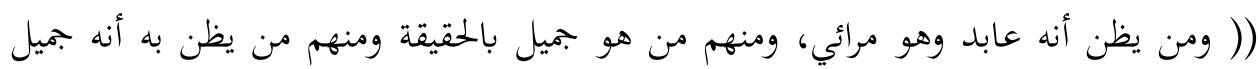

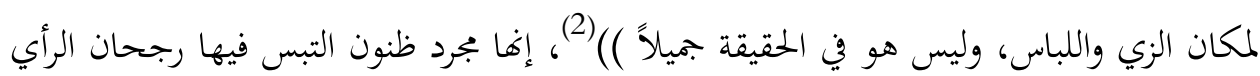
مع احتمال النقيض، وهذا ما يعني التوهم باستبدال الحقيقي بالزائف بغية التمحل والمماكره،

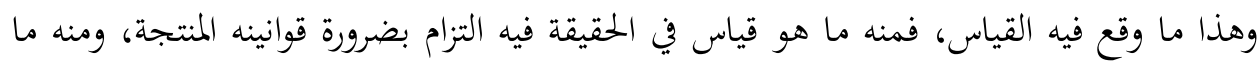
هو زائف غير منتج، لذا فهو يوهم بأنه قياس وهو ليس بقياس بل إنه ضرب من في القياس العقيم غير المنتج والمضلل يخفي على من لم يتعاط النظر في العقليات، ولم يجرب الأقاويل ويخبرها،

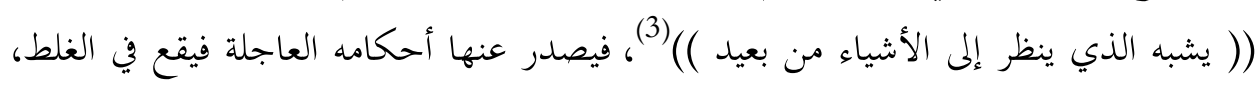
وكذلك الأمر في القياسات.

\section{2 تعريف القياس:}

كان ولابد أن يعرف أرسطو القياس على ضربين الأول القياس بإطلاق، والثاني القياس

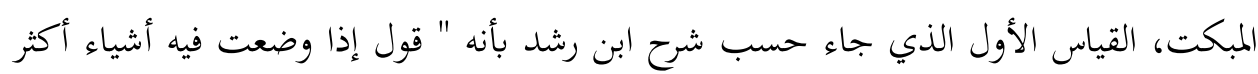

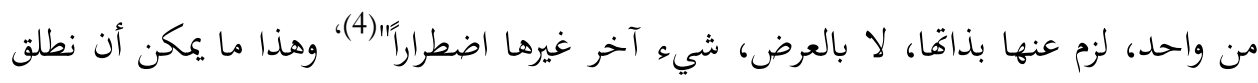

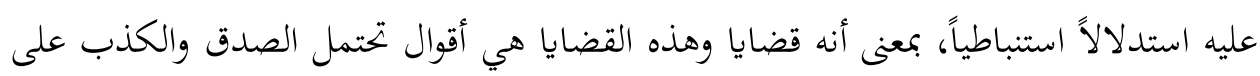
شكل قول -أي: لفظ مركب- قدم له بمقدمات معينة (أشياء) لا تقل على اثنين تلزم عنها بالضرورة شيء آخر غير تلك المقدمات أي ما يسمى بالنتيجة التي هي وليدة اقتران القضيتين

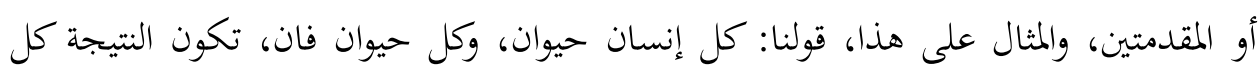

$$
\begin{aligned}
& \text { 1- أبو الوليد بن رشد، تلخيص السفسطة، ( مصدر سابق )، ص2. } \\
& \text { 2- نفسه، ص- أبو الوليد بن رش }
\end{aligned}
$$

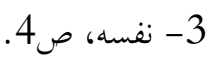

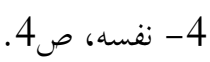


إنسان فان، أي أن فناء الإنسان جاء استدلالاً على فناء الحيوان ضرورة* وهذا حسب ما أراد أرسطو من تعريف القياس بصورة مجملة. أما تعريفه الثاني من القياس فقد خصه بالتبكيتات الحقيقة القائمة على الغلة بالحجة

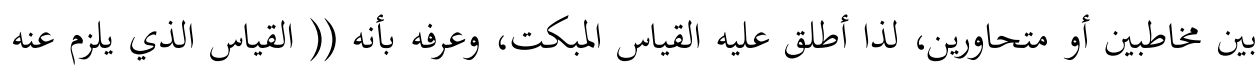

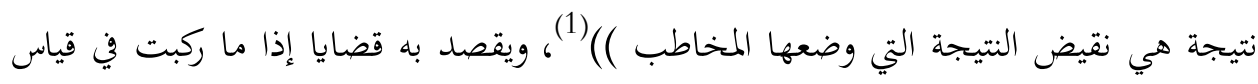
تسمى مقدمات، وعادة حسب القياس الحملي تتكون من مقدمتين ونتيجة، بغية الاستدلال على صدق دعوى أو كذبها، بمعنى أن الدعوى هي قضية يراد بها الحاكم على إثبات أو إبطال

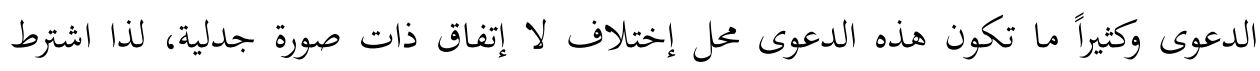

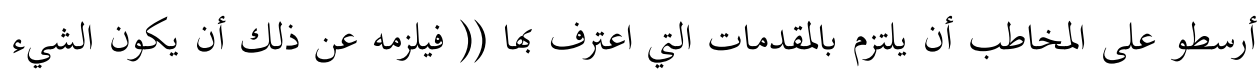

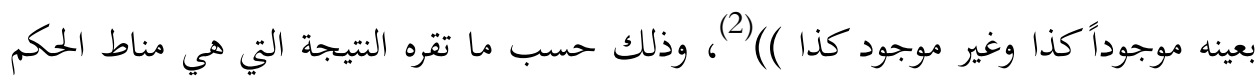
والمنحدرة أصلاً من الإلتزام والإعتراف بما جاء في المقدمتين المعروضتين أمام المتحاورين. والمثال

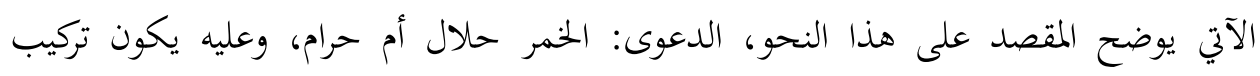
القضية كلآتي: الخمر مسكر (مقدمة أولى) كل مسكر حرام ( مقدمة ثانية) إذن، الخمر حرام حرام (نتيجة).

التحليل: الالتزام والاعتراف بأن الخمر يذهب بعقل شاربه أو متعاطيه وهذا ما هو مذموم ومرفوض إخلاقياً واجتماعياً، فهو حرام دينياً وعليه يكون الخمر حسب المبراب المشهورات

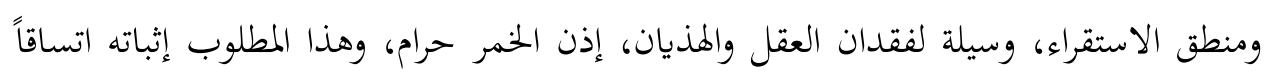
مع ما التزم به المخاطب واعترف به.

* اكتفيت بتقديم فكرة عامة عن القياس الحملي من الشكل الأول، ولم أتعرض لمكوناته وقوانينه لضيق المقام.

$$
\text { 2- أبو الوليد بن رشد: تلخيصالسفسطة، (مصدر سابق ) ص5 ص. }
$$




\section{3. الغلط والمفالطة:}

الغلط ظاهرة ملازمة لطبيعة الإنسان فيما يقول وفيما يسلك، فلا ملامة ولا عدل لأنه

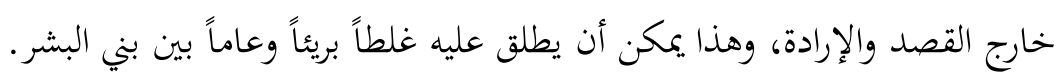

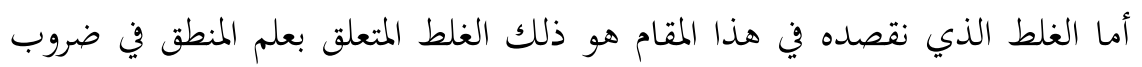
الاستدلال وقواعده ومبادئه وقد يكون غلط غير مقصود أيضاً، نتيجة التسرع في إصدار الحكم

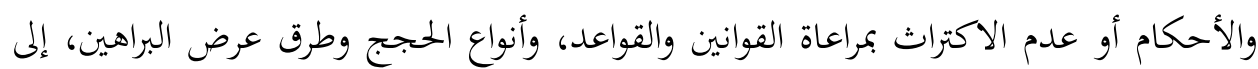
جانب عدم الالتزام بالقواعد العامة للغة في معاني ألفاظها ودلالة تراكيبها. أما الغلط المقصود فهو ضرب من المغالطة فهي مفاعله بين متخاطبين أو طرفين، يقصد أحدهما مغالطة الآخر، بمعنى تغليط مقصود بإرادة لإيقاع الخصم في الخطأ وتبكيته،وهذا ما يقصده أرسطو بالسفسطائية أو المغالطات كما أشرنا إليها آنفاً.

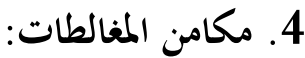

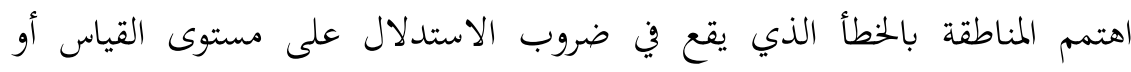
البرهان، بوصفها أغلاطاً منطقية سواء كانت مقصودة أم غير مقصودة، فنجد: زين الدين التساوِي (ت 540هـ) مثلا حصر مجامع الغلط في طريقتين: طريق التصور ( الحد والرسم)(1) وطريق التصديق (نظرية الحكم والبرهان) (2)، وهذا مما جعل المناطقة فيما بعد أن يصنفوا مسالك فئك

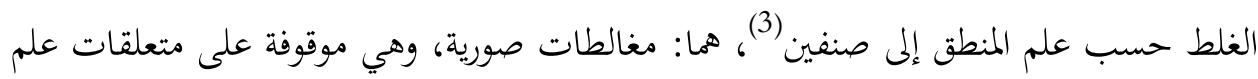
المنطق خاصة في قواعد وقوانين الاستدلالات المباشرة وغير المباشرة، إلى جانب ما يشمل عليها من استباط واستقراء وتمثيل ... وهذا الصنف من المغالطات الصورية، سوف لن نتطرق إليه

1- ينظر: البصائر النصرية، زين الدين الساوي، تحقيق: رفيق العجم، دار الفكر اللبنانية - بيروت ط1، 1993، ص ص 89

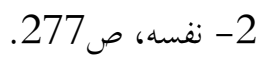
3- د. يُمَّمَ أحمد الرياقوسي، التعريف بالمنطق الأرسطي، دار الثقافة - القاهرة ( د. ت) ص360. 
ضمن هذه الورقة البحثية نظراً لطول مسلكه ودقة قوانينه المنطقية الصارمة، إذ أن الاختصار غير مجد فيه، وأمره يطول بين طيات هذه الورقة. أما الصنف الثاني، وهو الخاص بالمغالطات غير الصورية فهي التي تتعلق بمغالطات الغموض اللغوي، سواء في غموض العبارات والتراكيب التي صيغت فيها الاستدلالات أم ما يتعلق بالأخطاء النحوية، إلى جانب تحديد معاني الألفاظ ودلالات التراكيب، إذا أن اللغة هي الوحيدة المخول إليها التعبير عن الفكر، وهذا ما جعل وشائج القربي وثيقة بين اللغة والمنطق،

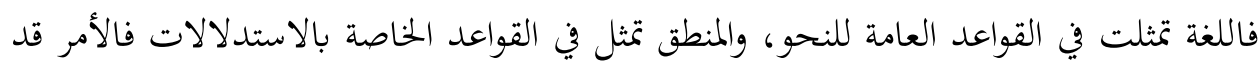

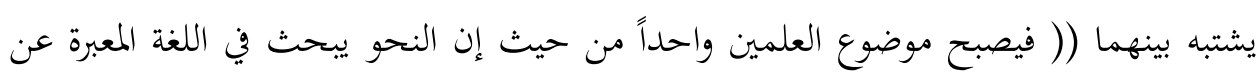

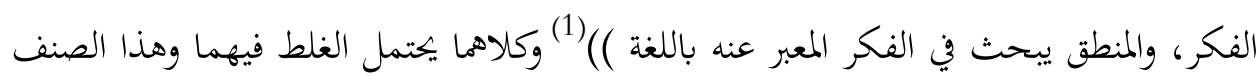
من المغالطات هو المعقود عليه البحث في هذه الورقة. بما أن المغالطات هي في جوهرها تظليلات مقصودة لغرض طمس الحقيقة والتنائي عنها. لذا تعددت مسالك المغالطات وأنواعها وتداخلت فيما بينها بحيث صعب تقسيمها وحصر أعدادها وتصنيف أغراضها ومقاصدها، وكلها تتمحور حول التبكيتات المظللة أي غير الحقيقية، لذا نجد أرسطو حصر هذه التبكيتات في مجالين (( الأول، تبكيتات داخل القول،

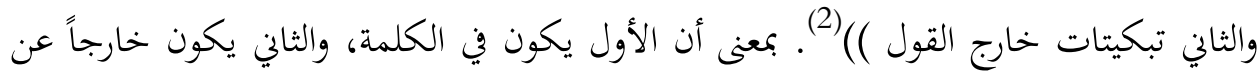

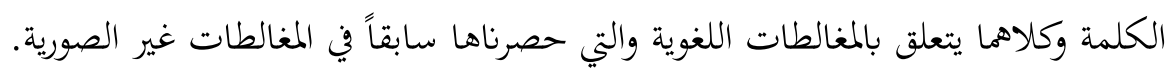
يرى أرسطو أن أشهر أسباب المغالطات أو التبكيتات المضللة (( هو ما يعرض للمعاني

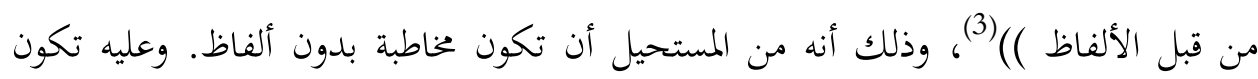
الألفاظ هي الأوعية الحاوية على المعاني أي أن الألفاظ هي التي أقيمت مقام المعاني، ومثار الغلط يكون في الألفاظ أو في كلتيهما معاً.

1- عبدالرحمن بدوي، المنطق الصوري والرياضي، وكالة المطبوعات - الكويت، ط:5، ص32.

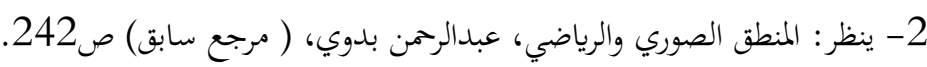

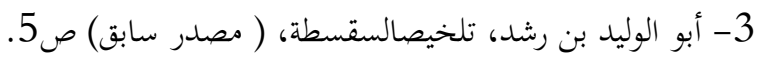


يبدأ أرسطو حسب تلخيص ابن رشد بشرح الغلط الذي يقع في الألفاظ، وسببه الوهم

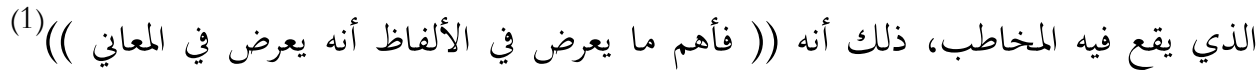
ومناط التوهم هو أن المتكلم يأتي بالألفاظ والأسماء ويقيمها مقام الأشياء أو الأمور كدلائل عليها، أي بدل أن تكون العناية بالمعاني، يتجه الوهم بالذهن على التعامل بالألفاظ الخلو من

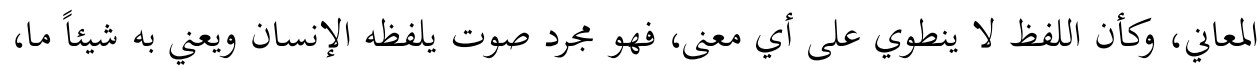

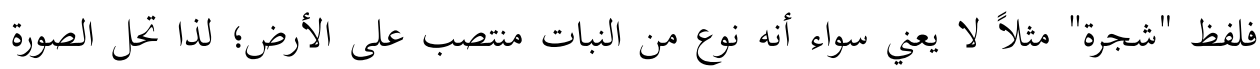

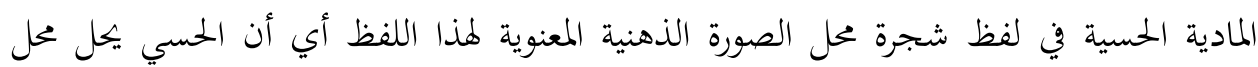
المعني.

هذا الغلط الذي سببه إقامة الألفاظ أو الأسماء مقام المعاني جاء حسب رأي أرسطو من طبيعة الألفاظ ذاتما، وأهمها: أ. الألفاظ ليست على شرج أو نضد واحد من حيث دلالتها على المعاني. ب. الألفاظ محدودة ومتناهية، وهذا على خلاف المعاني اللامحدودة واللامتناهية. ج. لا تتعدد الألفاظ وتتساوي بتعدد المعاني وتساويها. د. تختلف دلالة الألفاظ من صناعة إلى أخرى، ومن فن إلى آخر (2).

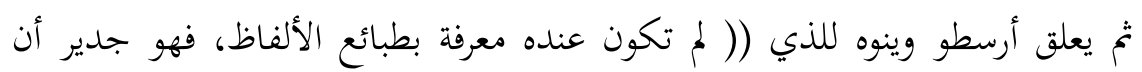

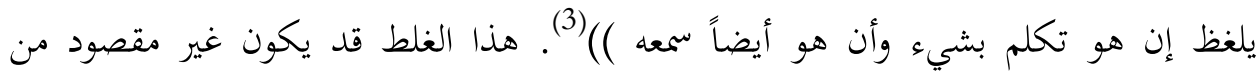

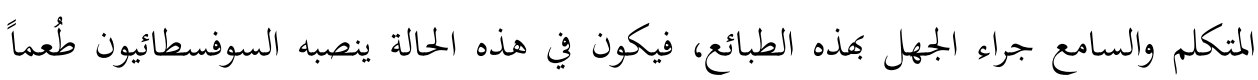
يصطادون به السامعين، لكي يوهموفم بأفم حكماء من غير أن يكونوا كذلك في الحقيقة، إنما

$$
\text { 1- أبو الوليد بن رشد، تلخيص السفسطة، ص5. }
$$

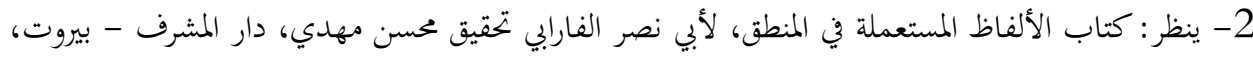

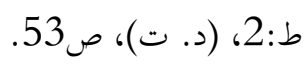

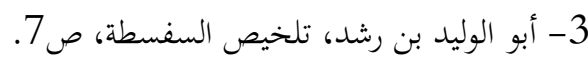


حكمة مرائية، ولكن (( عمل الحكيم بالحقيقة هو أن يكون، إذا قال، قال صواباً وإذا سمع كلام غيره ميز الكذب منه من الصواب ()) (1). خصلتان موجودتان في الحكيم بالحقيقية، أحداهما في ما يقوله والأخرى فيما يسمعه. 5. - 5 أجناس المخاطبات:

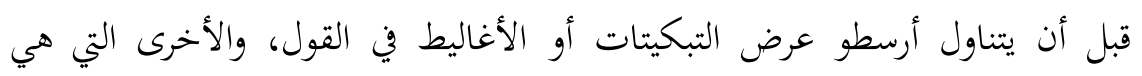

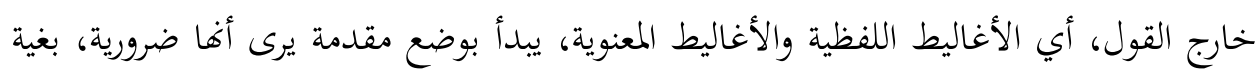

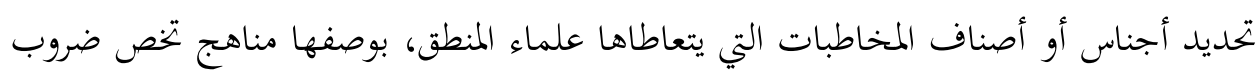
الاستدلالات المنطقية، لأن الأصل في التبكتيات أن تكون تبكينات حقيقة وتكون الغلبة فيها

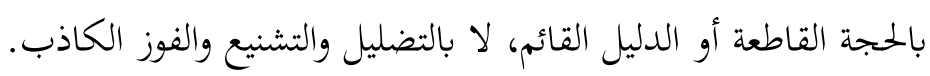

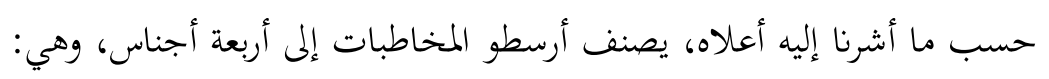

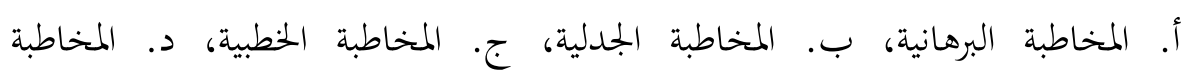

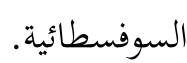

وهذه الأخيرة، أي: السفسطائية، أشار إليها أرسطو بأها جنس من الكلام موجود

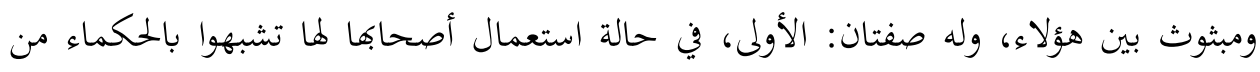

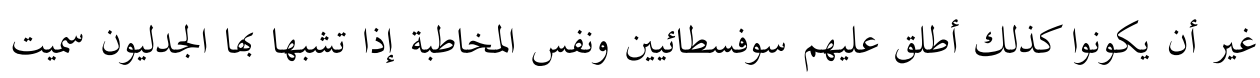

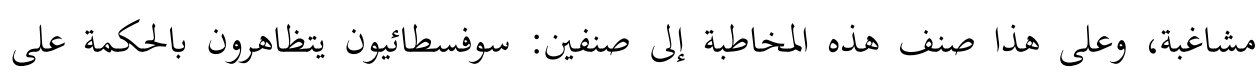

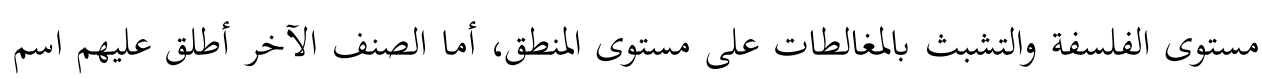
المشاغبين وذلك بإثارة الجلبة واللغط على المستويين الفلسفي والمنطقي.

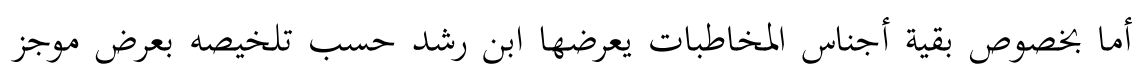

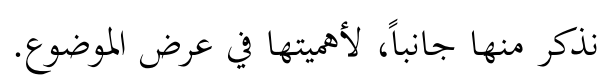

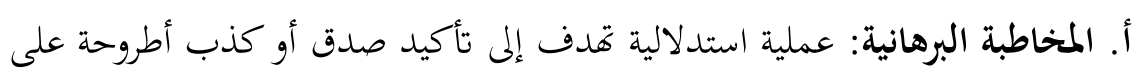

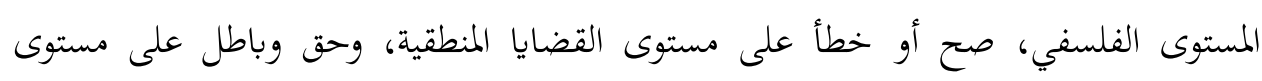
1- أبو الوليد بن رشد، تلخيص السفسطة، ص9. 
العقيدة والشريعة .. وهذه المستويات هي الاستدلالات التي يبني عليها البرهان، أما الاستدلالات في ذاها فهي تلك التي تترتب فيها القضايا منطقياً وتسمى في هذا الحال حججاً ويفترض فيها أن تكون صادقة صدقاً يقينياً ينتفي فيه الشك وإمكانية الشك، وهذا يعني البرهان في حالة صدق القضية، أما في حالة البرهان الذي يقيم كذب أو فساد القضية يسمى تفنيداً أو دحضاً.

يضع أرسطو حسب التلخيص شروطاً للمخاطبة البرهانية منها: 1- أن تكون المبادئ الأول الخاصة بكل علئ علم، أي البديهيات مثل: مبادئ عدم التناقض، والثالث المرفوع، والعلية. 2- مقدمات تسمى أصولاً موضوعة، فهي بمثابة مسلمات مثل: مسلمة التوازي (الخطان المتوازيان لا يلتقيان)، و (( تكون بين عالم ومتعلم بشأن أن يقبل ما يلقي إليه المعلم لا أن يفكر فيما يبطل به قول المعلم )(1). لأن المسلمات قابلة للإبطال والعناد أيضاً، فالمتعلم يعسر عليه كشق ما يلتئم عن هذه المسلمات في بادئ الأمر، وسوف يكتشفها في آخر الأمر. ب. المخاطبة الجدلية: يشير ابن رشد في شرحه لكتاب ( طويبقي) لأرسطو أن

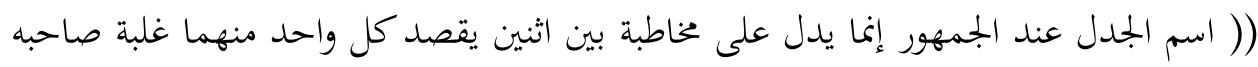
بأي نوع اتفق من الأقاويل )(|)، وهذا ما يعني أن الجدل فن النقاش والتحاور بطريقة الأسئلة

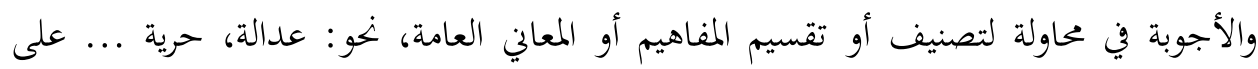
جانب التعريفات التي تحدد لنا جواهر الأشياء، فحسب رأي أرسطو أن التعريف (( هو القضية

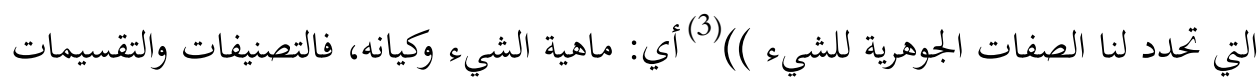
إلى جانب التعريفات تعد محددات حسب منهج المخاطبة الجدلية، وقد تكون أيضاً مكامن ولئ

1- أبو الوليد بن رشد، تلخيص السفسطة، ص11.

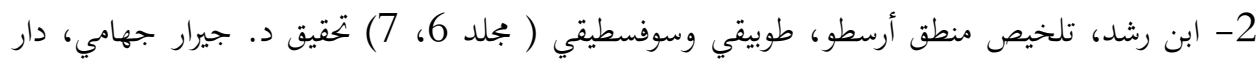

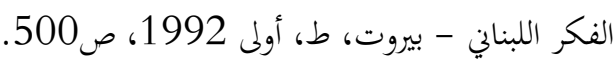
3- إمام عبدالفتاح إمام، محاضرات في المنطق، دار الثقافة - القاهرة، 1992 1992، صلون 96. 
للغلط والتغليط، جاء من الأمور المعنوية أو النظرية والأمور الحسية، فهذه الأخيرة يمكن أن

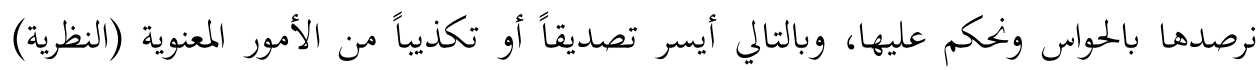

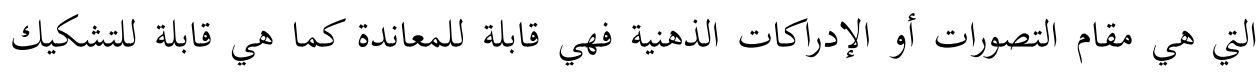
فيها.

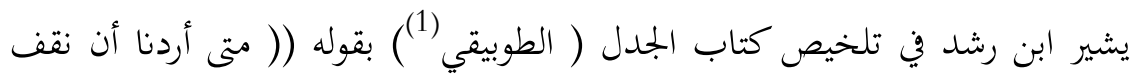

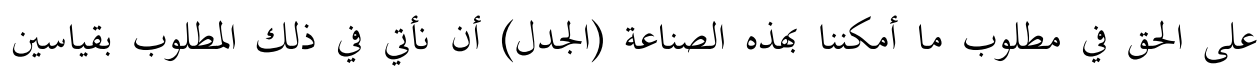

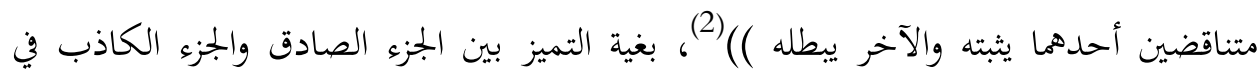

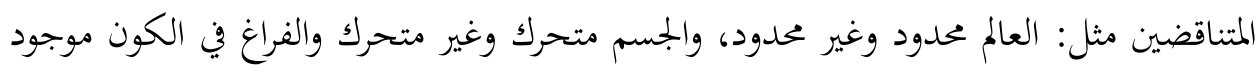

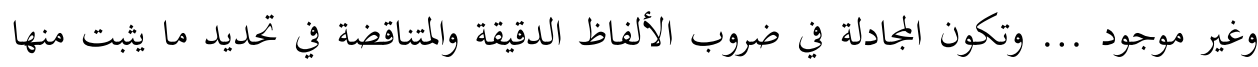
وما يبطل، فإذا أثبت طرف بطل الآخر، وهذا لن يتسنى إلا بفضل مطالب المقايسات.

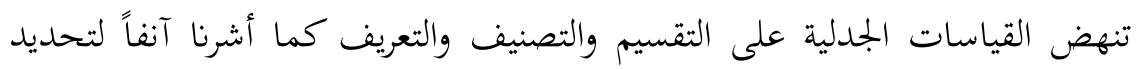

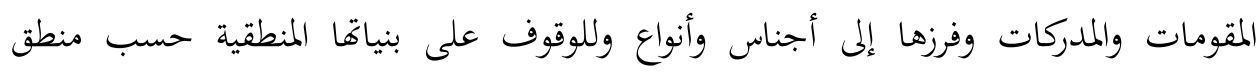

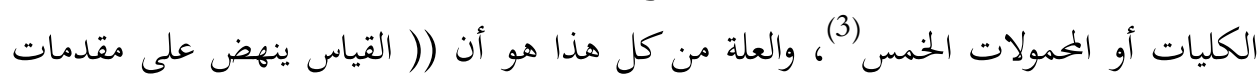

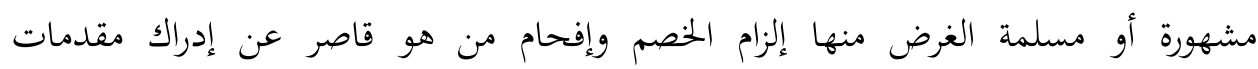

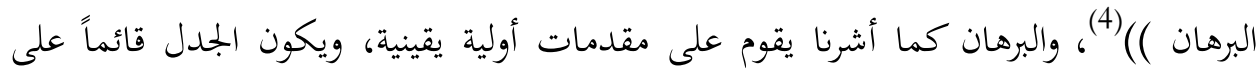

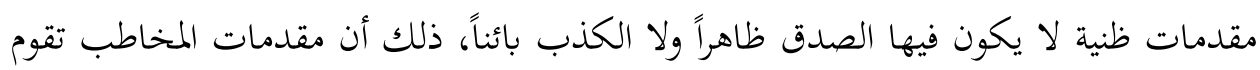

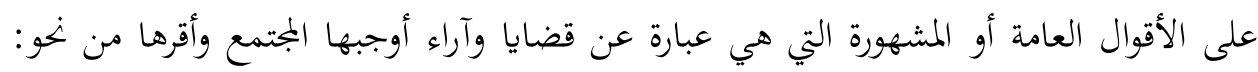

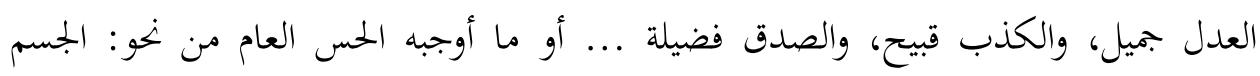

1- يقول الفارابي في كتاب الألفاظ المستعملة في المنطق ( م. سابق) إن لفظ الطوبيقا يعني المواضيع، وهي

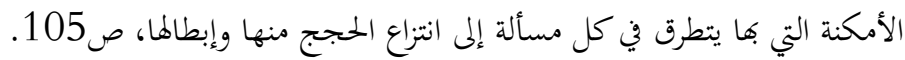

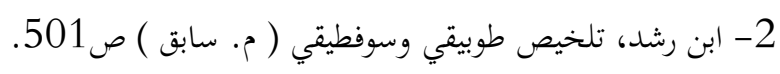

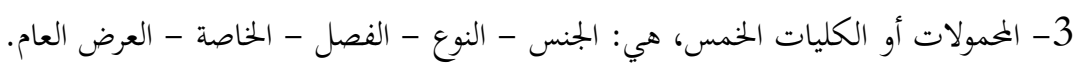

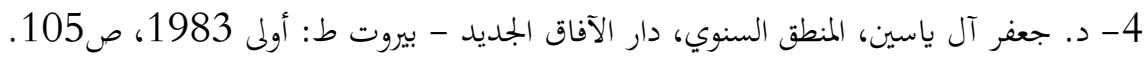


يسقط من أعلى إلى أسفل والشمس قرص له شروق وغروب، وعلى هذه المقومات يكون الجدل

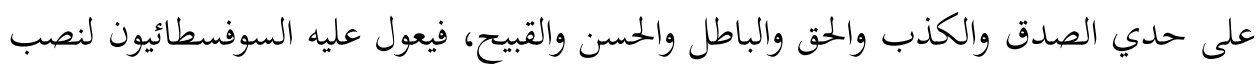
الغلط والمغالطة لمن ليس له دربه وقوة مجادله.

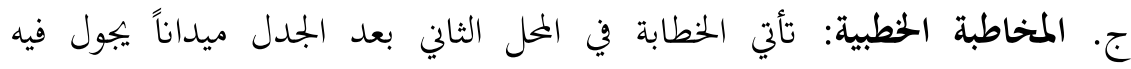

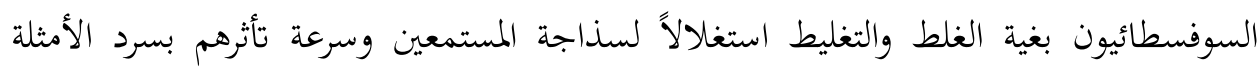

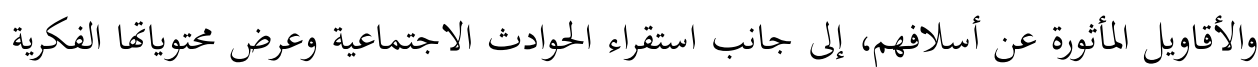

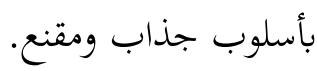

بقول الفارابي في كتاب الألفاظ: إن الجزء السابع من منطق أرسطو أسماه" ريطوريقا"

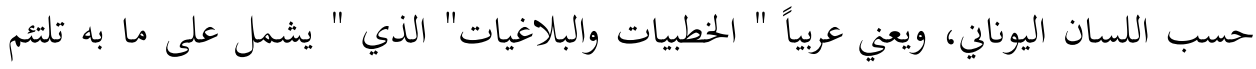

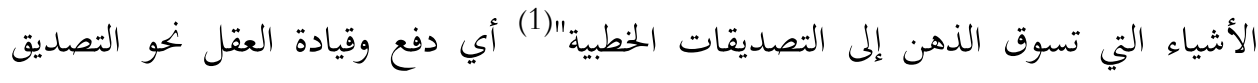

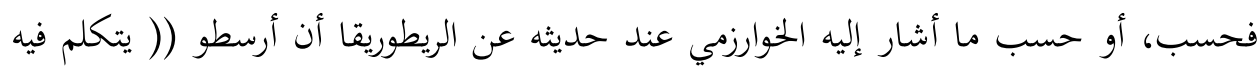

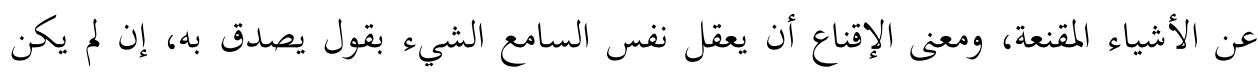

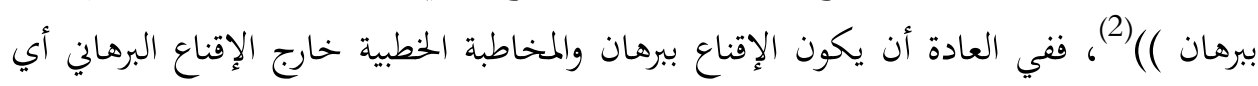

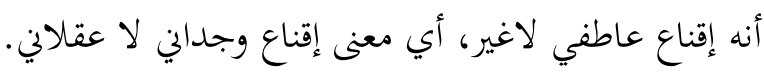

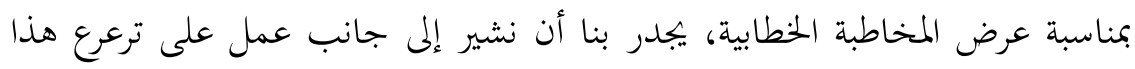

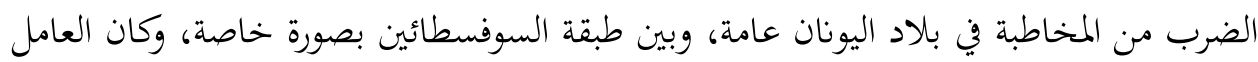

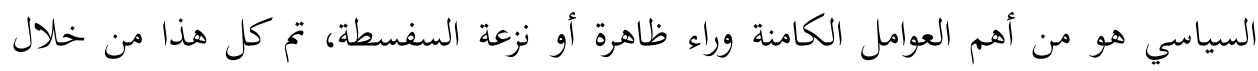

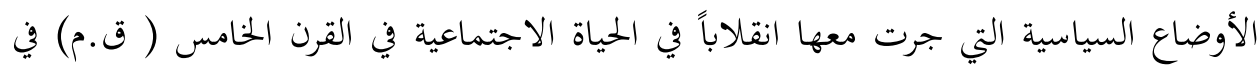

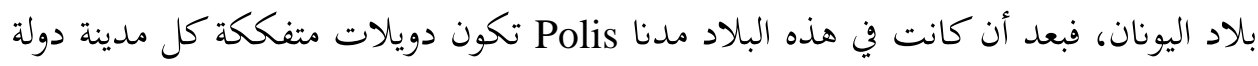

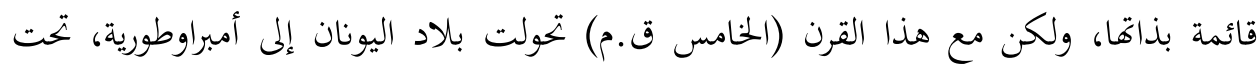

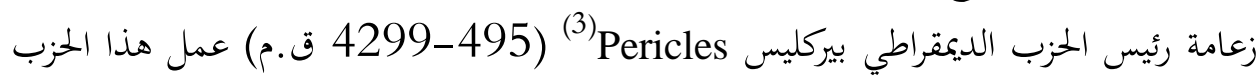

$$
\text { 3- 1- أبو نصر الفارابي، كتاب الألفاظ ( مرجع سابق) ص106. ينظر : طه حسين، نظام الإثبنين، دار المعارف دار المشرف - بيروت ( د.ت) ص177. مصر 1963، ص43. }
$$


إلى انقلاب في الحياة السياسية والاجتماعية معاً. تمثل سياسياً في الديمقراطية الارستقراطية والحرية الفردية المتمثلة في حرية الفكر وحق التعبير عن الرأي.

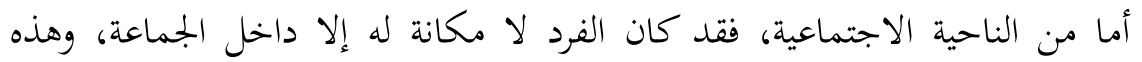

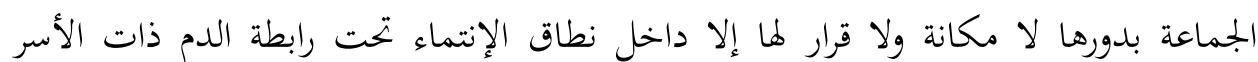
النبيلة، ولكن الذي حدث مع الديمقراطية والارستقراطية الجديدة انقلبت فيها الحياة السياسية

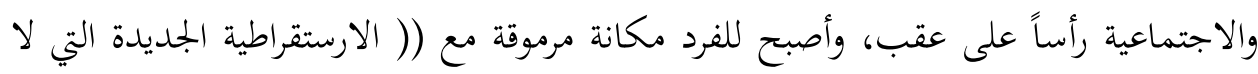

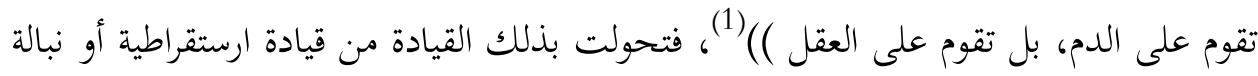

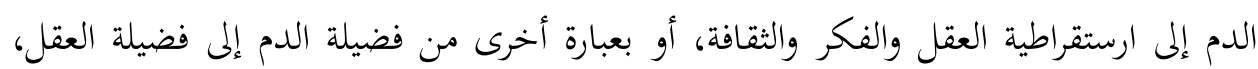
وفضيلة المواطن الحر، لا فضيلة الطبقة الاجتماعية المنتمي إليها.

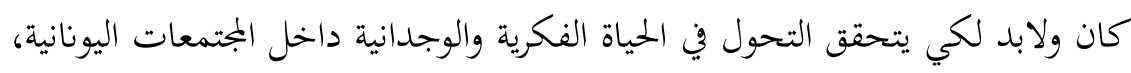
أن ينهض به طائفة السوفسطائين، وهم في الأصل (( معلمون يرتحلون من مدينة إلى أخرى بحثناً

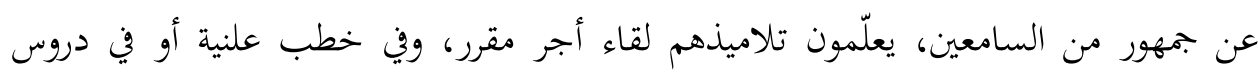

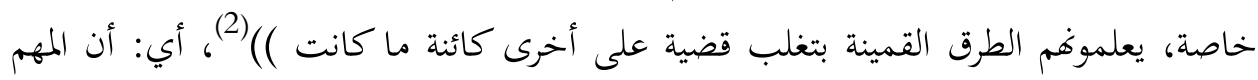

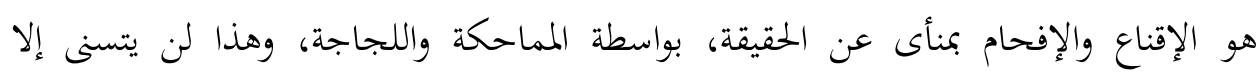

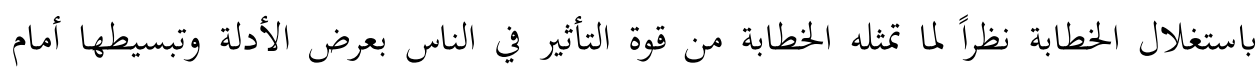
عامة الناس بسعة الألفاظ وقوة المعاني لذا وضعها أرسطو ضمن المخاطبات التعليمية وأفراد لها جزءا من منطقة. يبدأ أرسطو في المقالة الأولى من كتاب الخطابة يوضح مقارنة بين الخطابة "ريطوريقا" والجدل "ديالقطيقا" بقوله: (( أن الريطريقة ترجع إلى علم الديالقطيقية، وكلتهما توجد من من أجل ئل

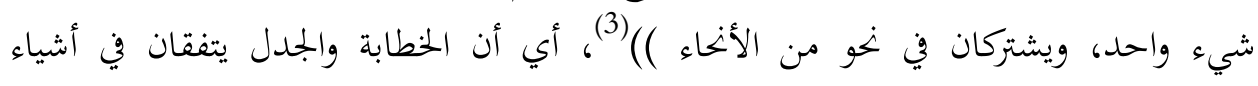
ويختلفان في أخر. فاتفاقهما إفما وضعا من وأجل شيء وئركان واحد هو الإقناع إلى جانب إفماء

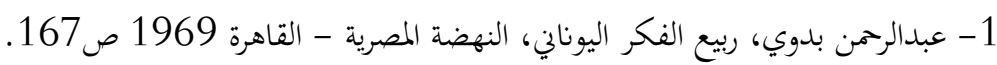

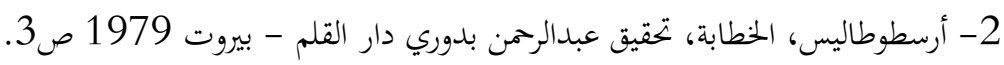
3- نفسه، ص3. أرسطوطالين، 
يسعيان إلى عرض وتوظيف المقاييس لإثبات المتقابلين أو المتناقضين أو المتضادين، بمعنى أن الن المانيات السامع إذا اقتنع بإثبات جانب كان عليه بنفي الآخر منطقياً.

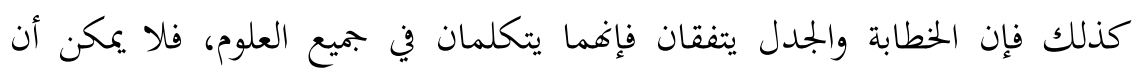

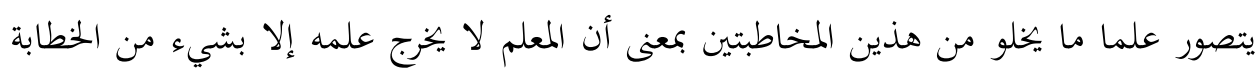

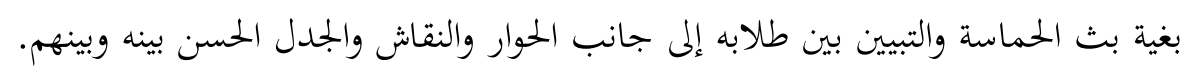

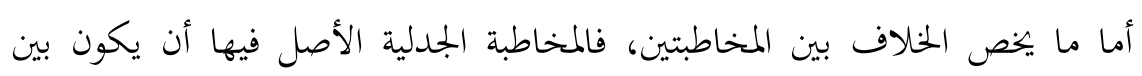

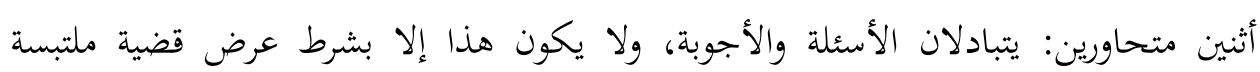

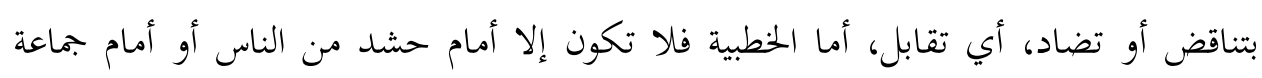
متعلمة.

وظف السوفسطائيون الخطابة والمدل بوصفهما أهم منفذ للفوز والنجاح المبني على فن

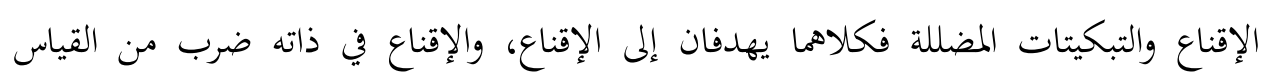

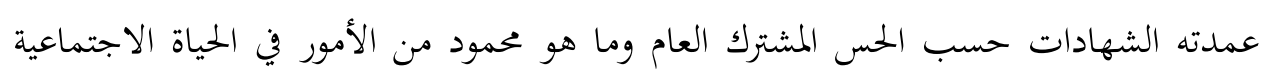

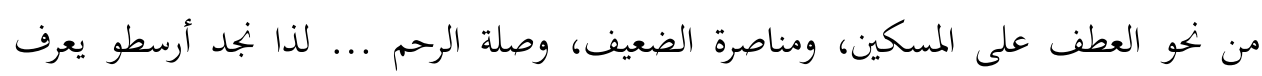

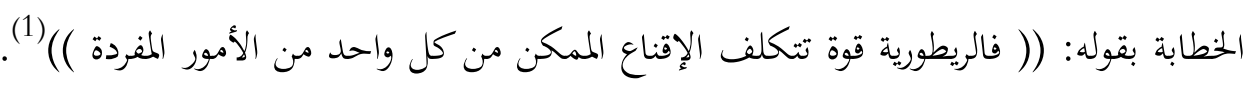

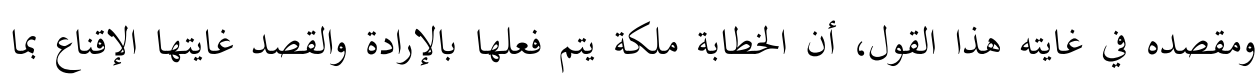

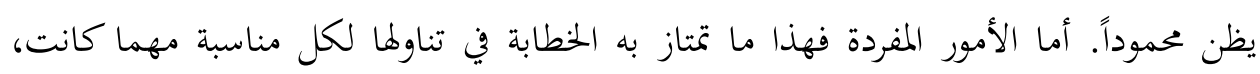

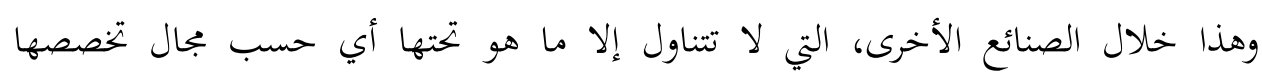

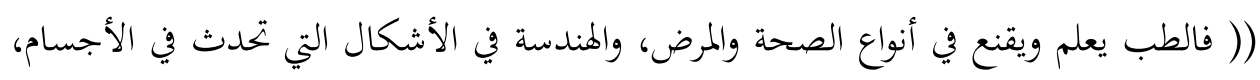

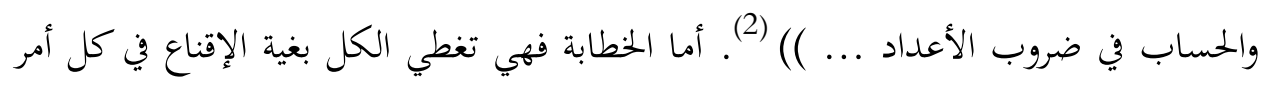
كائناً ما كان.

$$
\text { 2-1 - أرسطوطاليس، الخطابة، تحقيق: عبدالرمن بدوري، ص9. }
$$


كان غرض أرسطو في عرضه لأجناس المخاطبات الأربعة هو تبيان أصناف القياسات والأقاويل

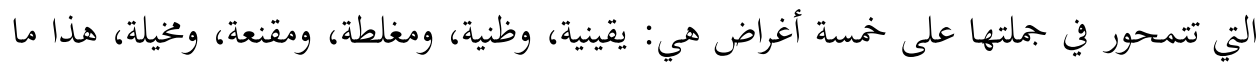
هو في ضروب المخاطبات والأقاويل، غير أن السوفسطائيين لهم أغراضهم ومقاصدهم في تطويع هذه الأغراض لترويج ضلالاتم، يقول أرسطو: (( فهذه الأغراض الخمسة التي يؤمها السوفسطائيون )) (1) ثم يشير إلى أكثرها مقصوداً عندهم (( هو التبكيت ثم يتلو ذلك التشنيع على المخاطبْ، ثم يتلو ذلك التشكيك، ثم يتلو ذلك استغلاق الكلام واستحالته، ثم يتلو ذلك

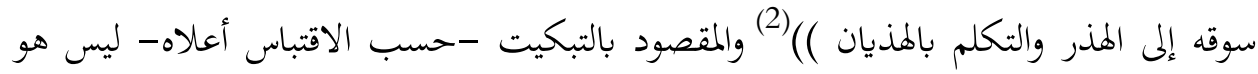
الغلبة بالحجة والبرهان الذي محله اليقين بل الغلبة بالحجة الواهية. وأما التشنيع إثبات الأشياء الكاذبة وفرضها على المخاطب ولو قبحه وفضحه في رأيه واستهان بعقله، واستغلاق الكلام

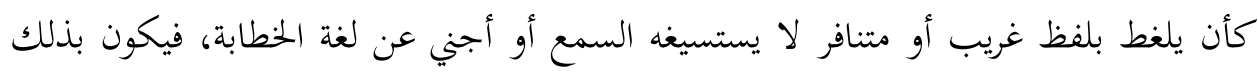
الهذر والهذيان.

\section{أ. مغالطات داخل القول:}

أشرنا سابقاً إلى مكامن المغالطات(3) والأخطاء التي أهتم بها المناطقة على مستوى المول الاستدلالات والبراهين، ونخصص في هذا المقام المغالطات المقصودة التي تتعلق بالغموض اللغوي من قبل الألفظ والمعاني فكل ما في المنطق من قياسات واستدلالات وأقاويل ومخاطبات برهانية كانت أو جدلية أو خطابية... كل هذا عمليات فكرية تقوم داخل الذهن ثم يأتي دور العقل في

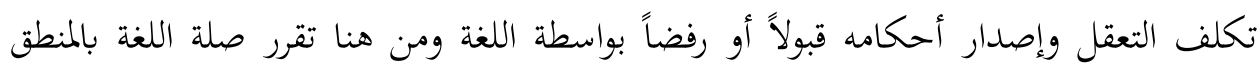

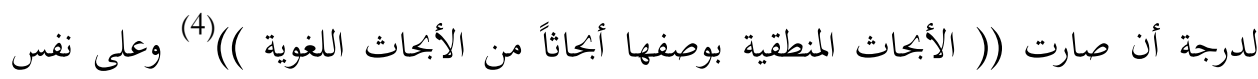
النسق فإن الأبحاث اللغوية لا تنفك عن الأبحاث المنطقية بوصفها أبحاثاً في الفكر وي التعبير

1- أبو الوليد بن رشد، تلخيص السفسطة ص14.

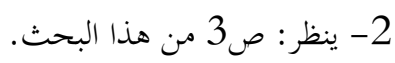
3- 3 نفسه، ص15. 4- د. ثُمَّمَ أحمد السرياقوسي، التعريف بالمنطق الأرسطي ( مرجع سابق) ص18. 
عنه و (( أرسطو قد وصل إلى كثير من التصنيفات المنطقية بواسطة دراسته للغة ونهوها )(1)، فاللغة من حيث أها ظاهرة اجتماعية للتواصل ومن حيث هي ظاهرة معرفية ذات منحى علمي للفهم والتفهيم والبيان والتبيين، إلى جانب أن لها مناهجها وقوانينها المحكومة، وعليه كانت

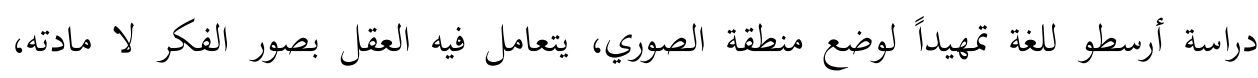

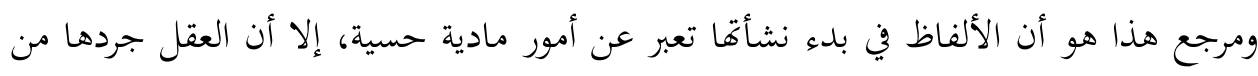

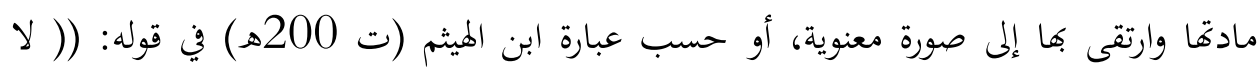

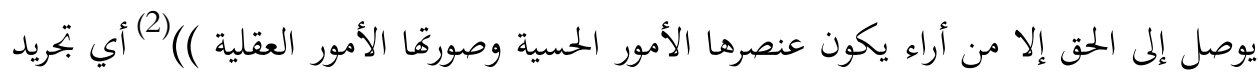
الحسي للوصول به إلى ما هو عقلي، وهذا الأخير لن يتأتى إلا بنوع من التجريد والاستدلال.

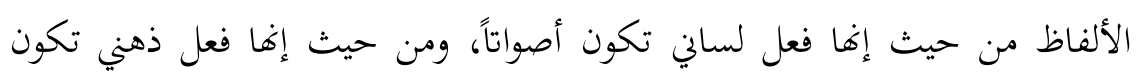
معان ثابتة في النفس، أما من حيث إفا فعل عقلي تكون مدركات لأنواعها وتقسيماتحا ومشتقاتما وتراكيبها وقواعدها العامة هذه الأفعال هي القاعدة أو الأصل التي يؤسس عليها المنطق تصوراته وتصديقاته واستدلالاته لتحقيق الأحكام اليقينية الصادقة، أما السوفسطائيون

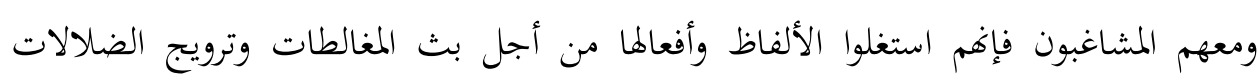
والشكوك.

يرى أرسطو أن التبكيت والتغليط لا يكون إلا من قبل الألفاظ والمعاني والذي

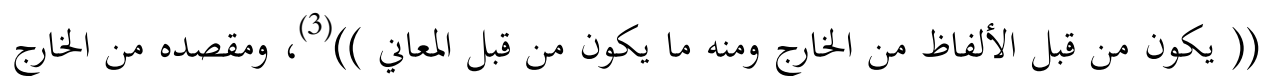
هي تلك الأصوات التي تتركب من بعض الحروف الهجائية التي يتلفظ بها المتكلم أثناء الكلام

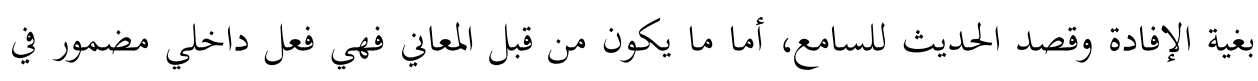

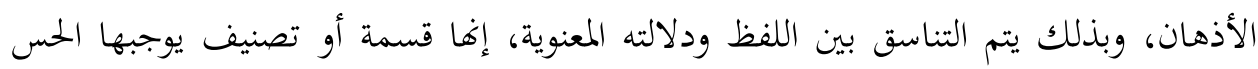
المنطقي منعاً للتداخل والاضطراب بين المفاهيم.

$$
\text { 1- 1 عبدالرحمن بدوي، المنطق الصوري ( مرجع سابق) ص33. }
$$

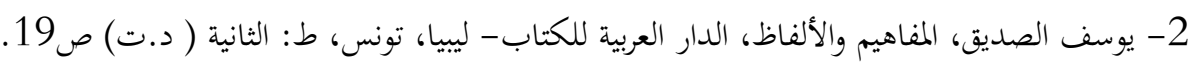
3- أبو الوليد بن رشد، تلخيص السفسطة ص14. 20. 
يبدأ أرسطو حسب تلخيص ابن رشد يكصر أصناف المغالطات إلى ستة أصناف، وهي على

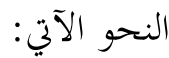

1. اشتراك اللفظ المفرد، 2. اشتراك التأليف، 3. الذي من قبل الإفراد، 4. من قبل

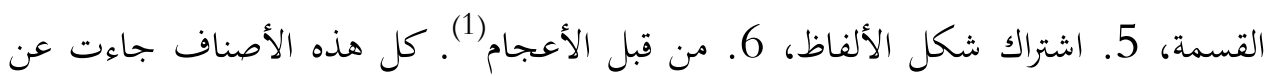
طريق الاستقراء والقياس لغة ومنطقاً.

أما بخصوص اشتراك اللفظ هو التلفظ بكلمة لها عدة معان حقيقية (في جوهرها) لا لا جمازية. وهذا الصنف من الاشتراك هو أقوى الأسباب المؤدية للغلط والتغليط. والمثال عليه

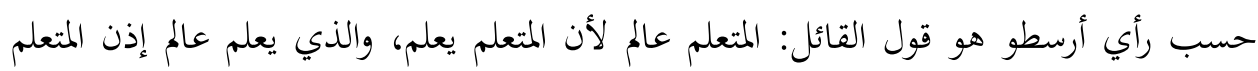

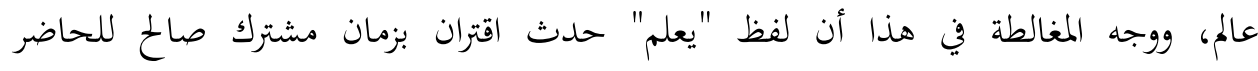
والمستقبل، إلى جانب اشتراك اسم التعليم، فالعالم يتفهم وييتهد ويستنبط بنفسه، والمتعلم يستفاد

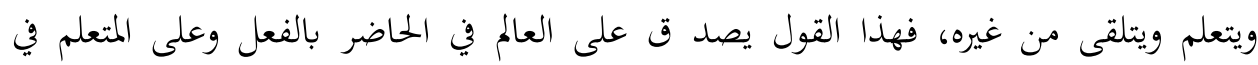
المستقبل أما اشتراك التأليف فهو أصناف فقد يكون من قبل التقديم والتأخير وقد يقع بالقوة فيه

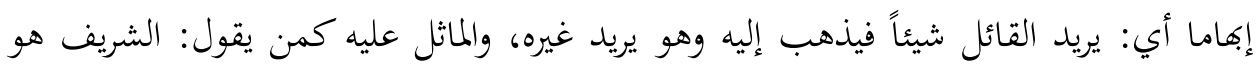

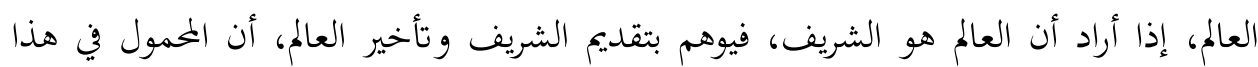

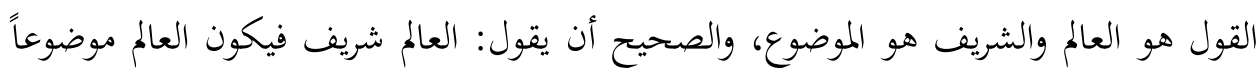

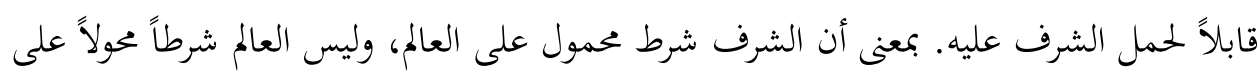

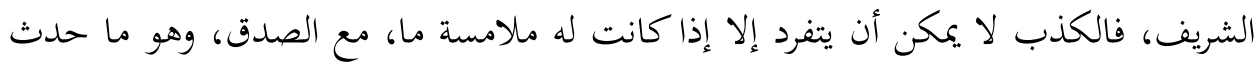

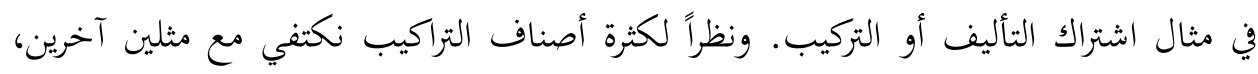

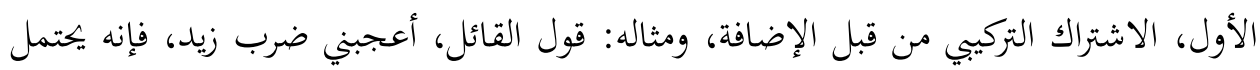

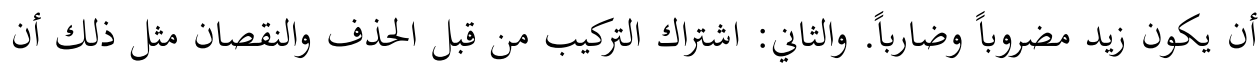

$$
\text { 1- 1- أبو الوليد بن رشد، تلخيص السفسطة، ص16. }
$$


يقول القائل: إن الذي لا يمشي يستطيع يمشي، والذي لا يكتب يستطيع أن يكتبن فهذا القول

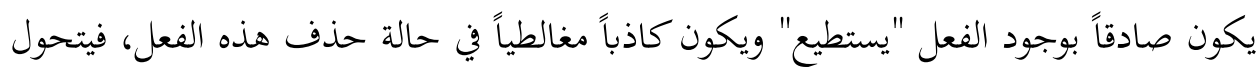

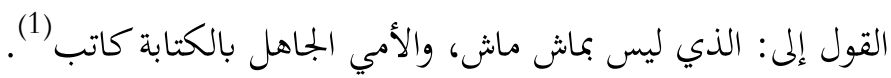

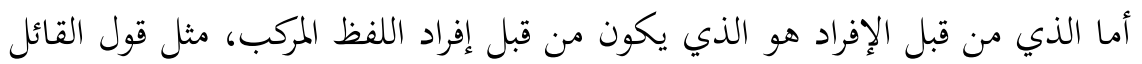

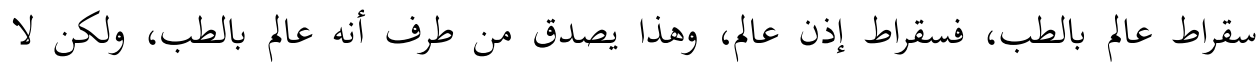

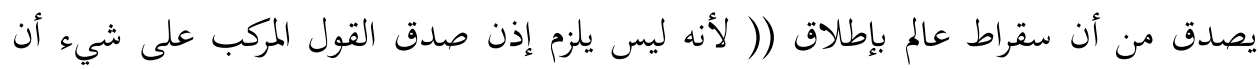

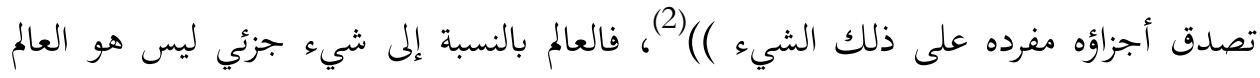
بإطلاق.

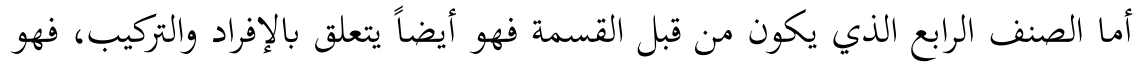

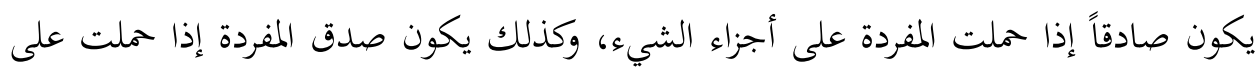

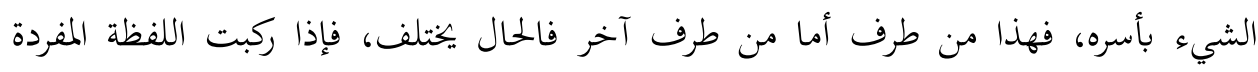

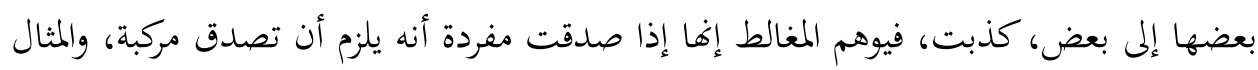

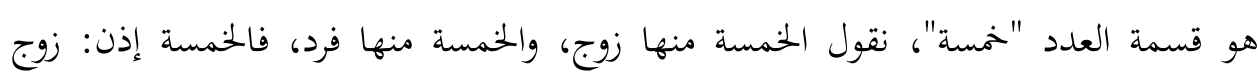

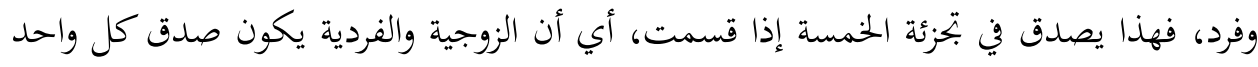

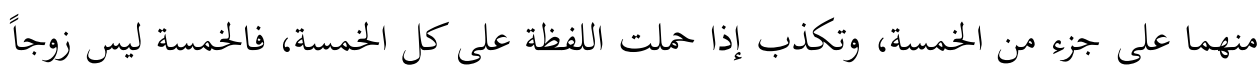

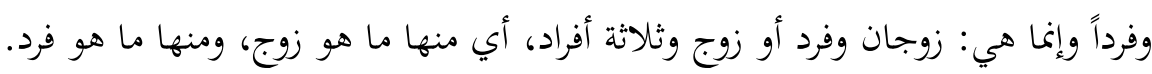

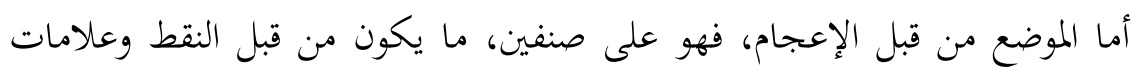

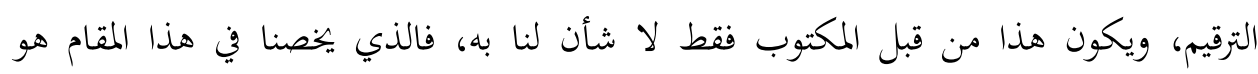

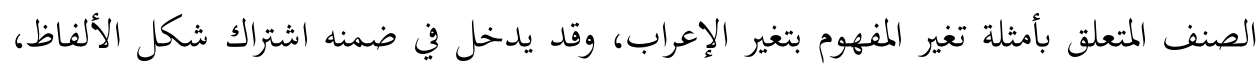

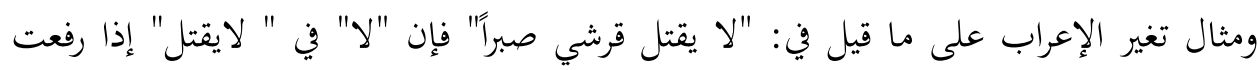

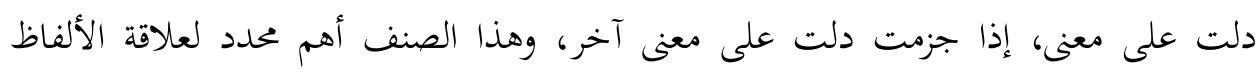

$$
\begin{aligned}
& \text { 1- ينظر : تلخيص السفسطة، ابن رشد، ص20. } \\
& \text { 2- أبو الوليد بن بنغص رشد، تلخيص السفسطة، ص21. }
\end{aligned}
$$


بلمعاني وللوظائف النحوية في عمومها. وأما أمثلة اشتراك شكل الألفاظ مثل أن تكون صيغة لفظ المذكر هي نفس صيغة لفظ المؤنث مثل (ولد) (وقمر). أو مثل صيغة لفظ ملفوظ

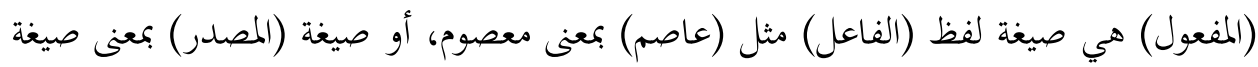
(المفعول) مثل (لفظ) بمعنى (ملفوظ) و(أكل) بمعنى (مأكول)، ويترتب على كل هذا هذا أوهام،

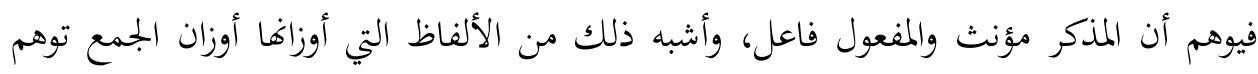

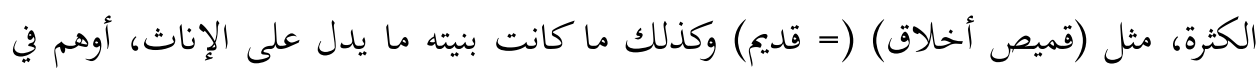

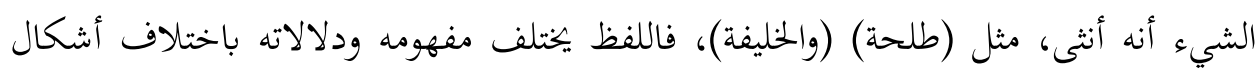

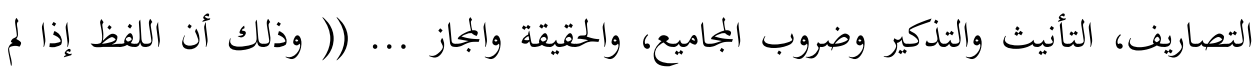

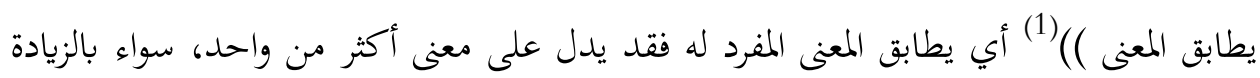

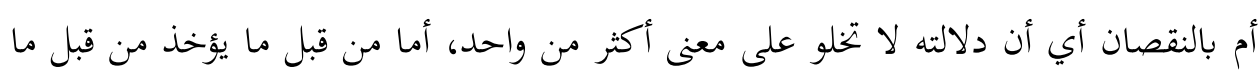

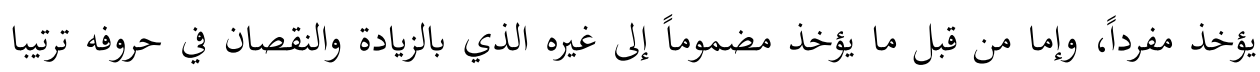

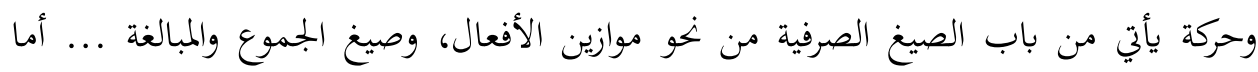

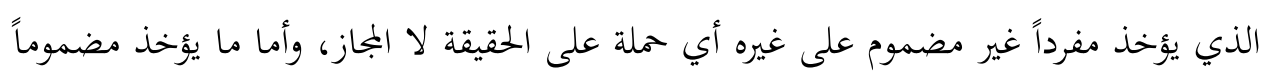

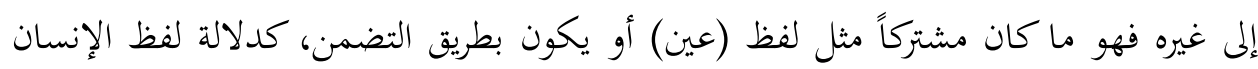
على الحيوان، أو دلالته الالتزام كدلالة لفظ السقف على على الحان لمائط.

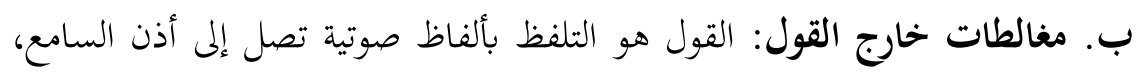

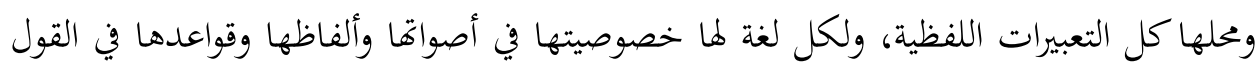

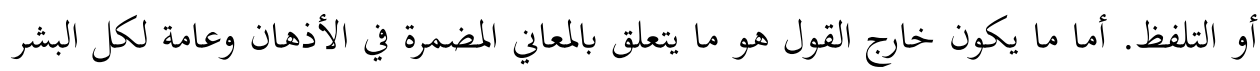

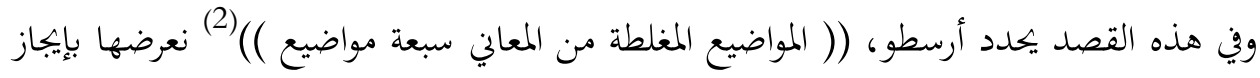

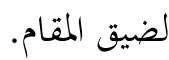

1- 1أبو الوليد بن رشد، تلخيص السفسطة، ص27.

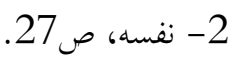


أحدهما: إجراء ما بالعرض مجرى ما بالذات، ومعنى العرض هو كل ما لا يقوم بذاته،

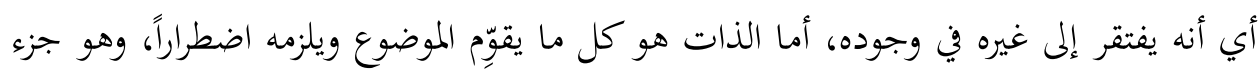

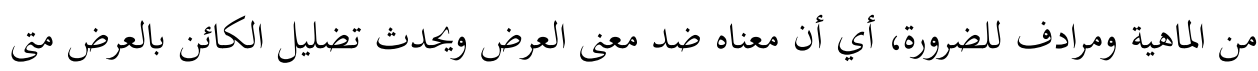

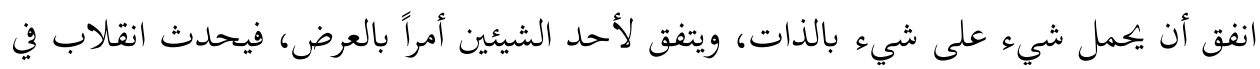

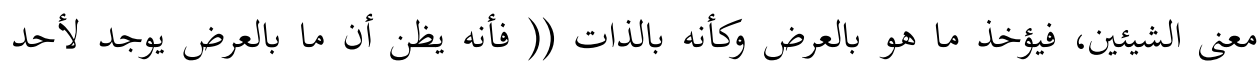

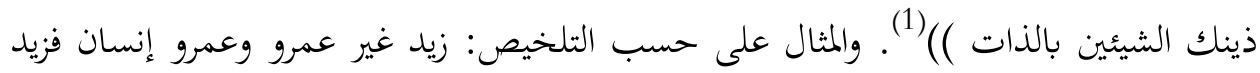
غير إنسان. غيرية زيد لعمرو بالعرض لا بالذات فكان الغلط عندما حمل الغيرية عليهما بالذات، فأخطأ في كون زيد غير إنسان، في الوقت أن الإنسانية في كليهما بالذات لا بالعرض. الثالي: التغليط في أخذ المقيد مطلقاً، حسب المعنى أو الصورة الذهنية أي أن الأخذ بهذين المتقابلين، يكون المقيد في مقابل المطلق، فالمقيد، وقع تحت تقيدات كثيرة، منها تقييد

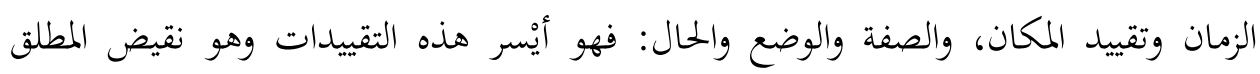

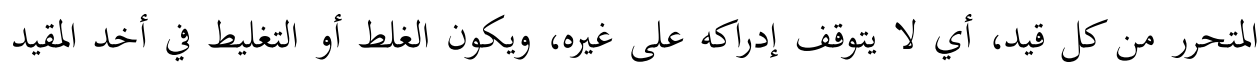

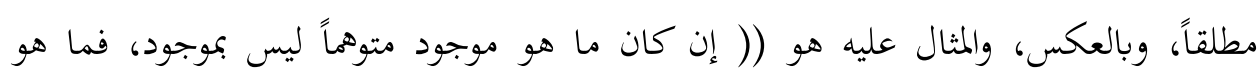
موجود فليس بموجود )(2)، وهذا القول يصدق إذا قيد أي قيد بمكان أي أنه ليس بموجود

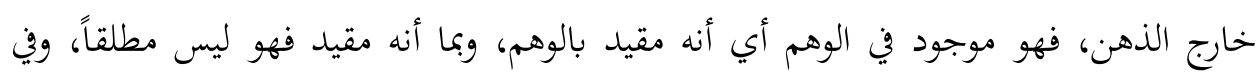
هذا الموضع يكون الشيء صادقاً، فالغلط الذي يكون في الخلاف بين المطلق والمقيد في المعنى

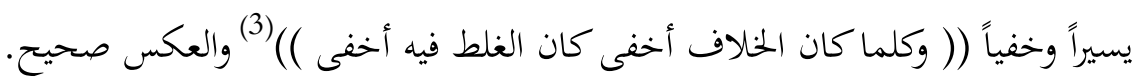
الثالث: الغلط الذي يقع من قلة العلم بشروط التبكيت يحدد أرسطو هذا الصنف من

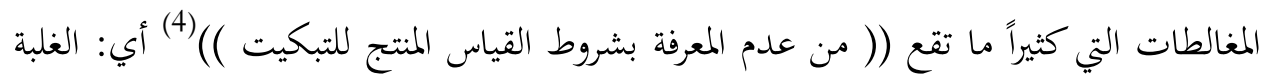

$$
\text { 1 - 1- أبو الوليد بن رشد، تلخيص السفسطة، ص25 } 20
$$


بالحجة والبرهان، لا كما يريد السوفسطائيون، وهذا لن يتأتى إلا بالقياس الذي عرفه أرسطو

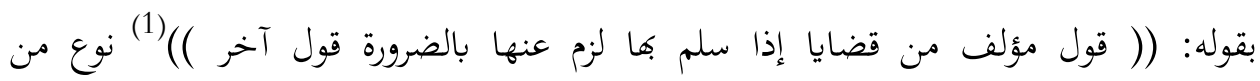

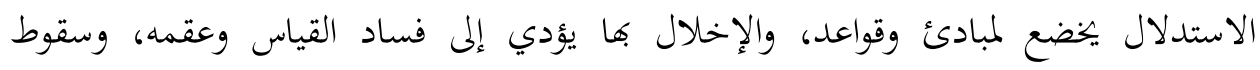

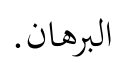

يرى أرسطو أن من ضمن الجهل بشروط التبكيتات القياسية هو عدم معرفة قوانين التقابل، وخاصة فيما يتعلق بالتناقض والتضاد وما دخل تحتهما، يقول الساوي في التناقض إنه إنه

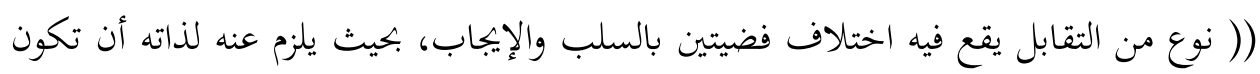

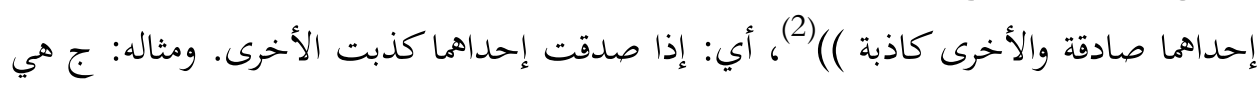

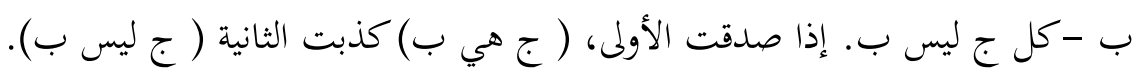

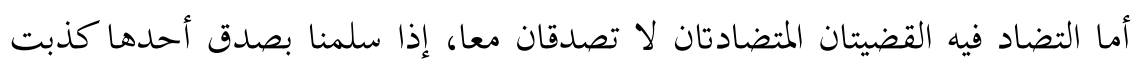

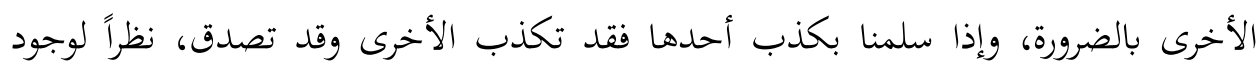

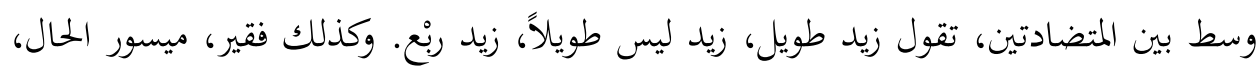

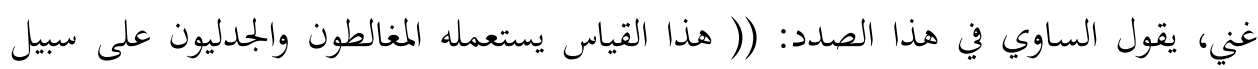

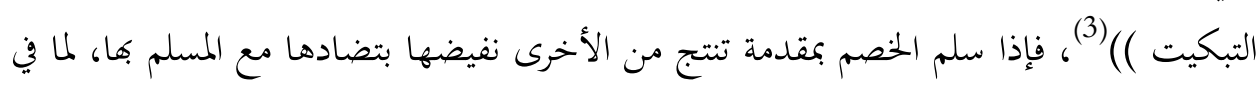

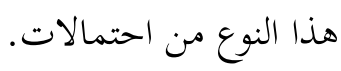
نكتفي بهذين الصنفين، من قانون التقابل، فهما الكفيلان لمعرفة ما جاء في مستعمل

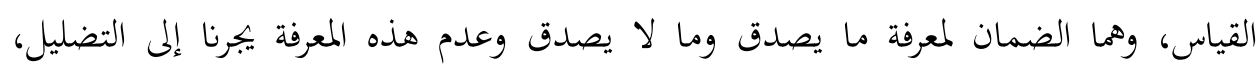

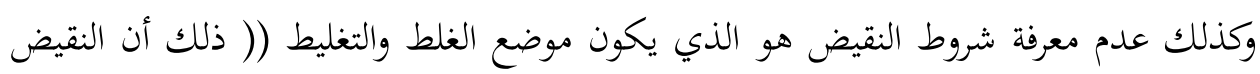

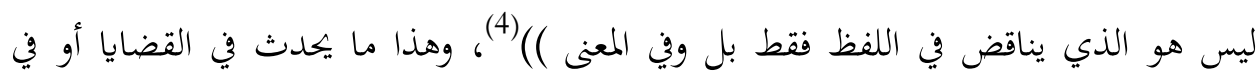

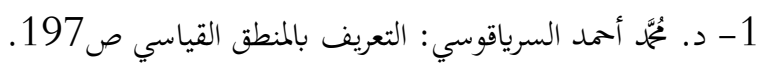

$$
\begin{aligned}
& \text { 2- } 1 \text { - زيد الدين الساوي: البصائر النصرية، ص121. } \\
& \text { 3- المرجع ننسه، ص202. } \\
& \text { 4- أبو الوليد بن رشد، تلخيص السفسطة، } 32 .
\end{aligned}
$$


القضية الواحدة التي هي التعبير اللفظي عن الحكمم بعد أن تربط بين لفظين كانا منفصلين إثباتاً

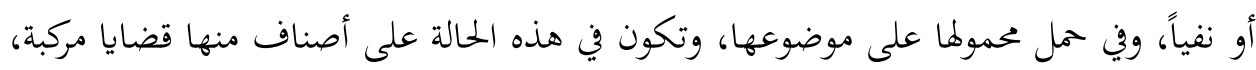
وقضايا شرطية، منها المنفصل، ومنها المتصل وقضايا موجبة وأخرى سالبة ... وقد تكون الألفاظ تناقض بعضها بعضا نكتشفها بيسر، ولكن الذي يعسر كشفه هو تناقض المعاني خاصة في القضايا المتقابلة كما وكيفا، والمثال الذي يأتي به أرسطو هو (( أن يضع واضع أن هذا ضعف لهذا، فبين مبين أنه ليس بضعف )(1)، فهذه قضية أصدرت حكماً (( ويكون قولنا فيه

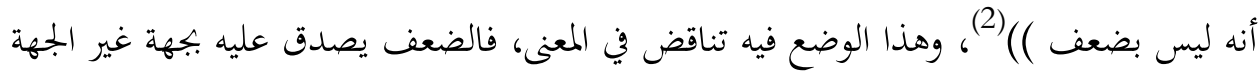
التي يصدق بها أنه ضعف، (( مثل أن يصدق أن الخط ضعف للخط من جهة الطول وغير

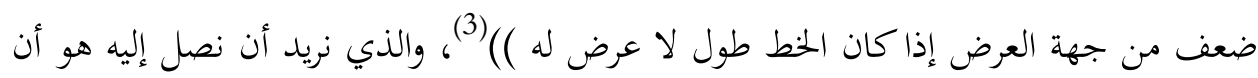
الشيء الواحد بعينه قد يكون ضعفاً وليس بضعف، فإغفال جهة هذه المعاني يكون التبكيت مغالطياً في اللفظ والمعنى، ذلك أن المعنى صورة يجملها اللفظ، وما الألفاظ إلا أدلة على إثبات

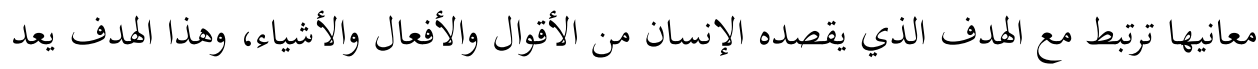
من شروط التبكيت أو الاستدلال الصحيح، وخلافة يكون مصدر للغلط غير المقصود أو الغلط يلط المقصود.

الابع: التغليط الذي يقع من قبل موضع اللاحق، ويقصد لزوم حكم أمر ما، أي أن

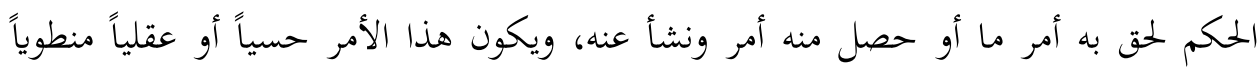
على معنى، ومثاله الحسي (( أنه إذا كان عند الإنسان أن كل حامل منتفخة الجوف، قد مل يغلب

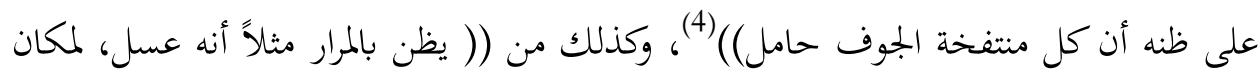

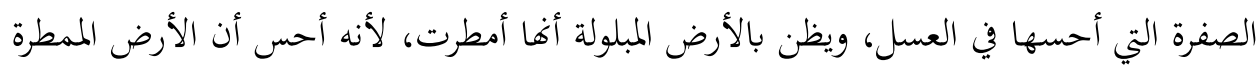

$$
\begin{aligned}
& \text { 1- أبو الوليد بن رشد، تلخيص السفسطة، ص3. }
\end{aligned}
$$

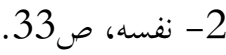

$$
\begin{aligned}
& \text { 3- نفسه، ص33. }
\end{aligned}
$$

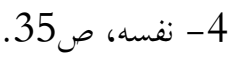




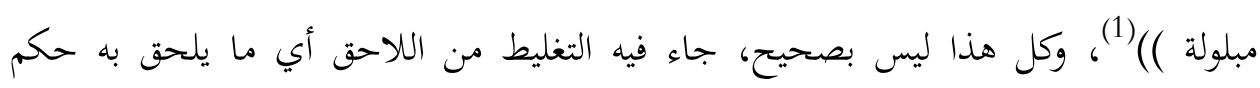

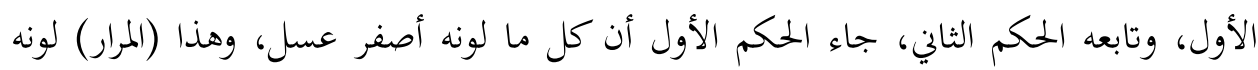

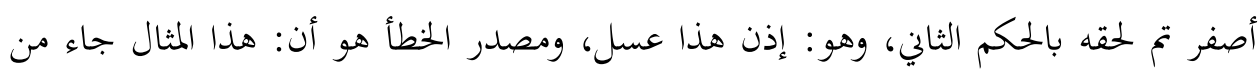

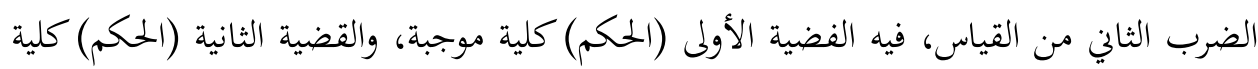

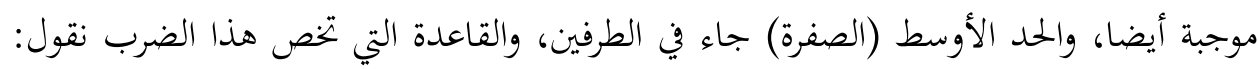

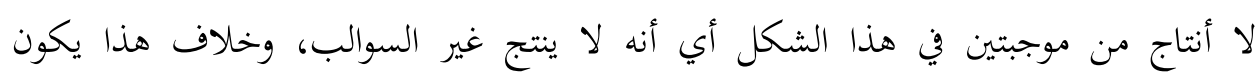
خاطئا (2)، وقس على هذا من المثال بقية الأمثلة.

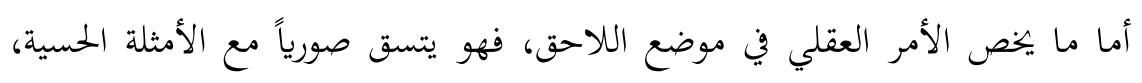

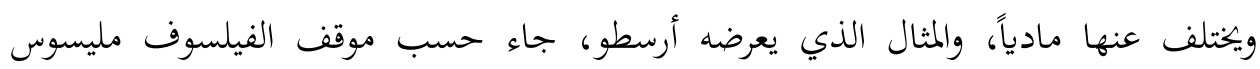

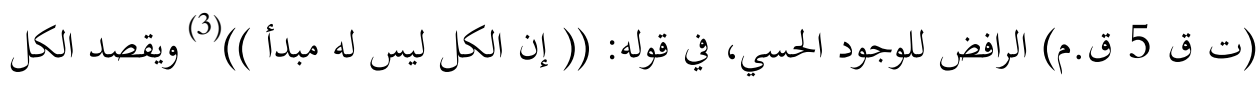

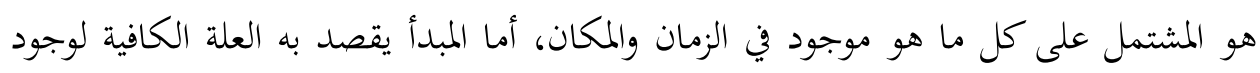

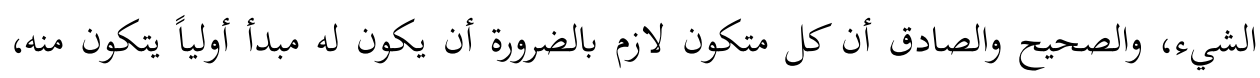

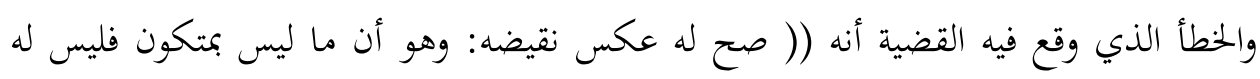

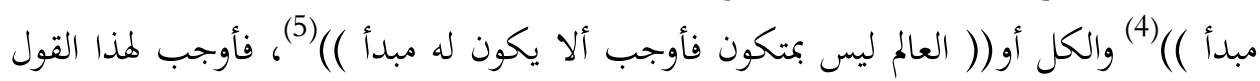

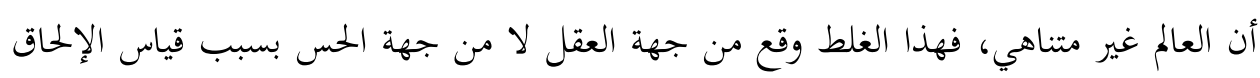

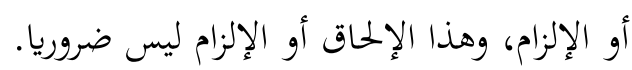

الخامس: المصادرة على المطلوب، تتعلق هذه المصادرة بالقياس المكون من مقدمتين

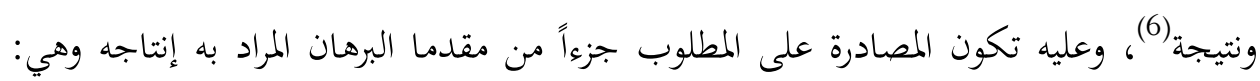

$$
\text { 1- أبو الوليد بن رشد، تلخيص السفسطة، ص36. }
$$

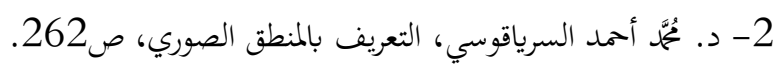

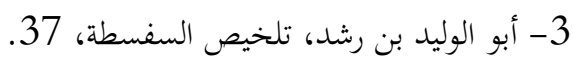

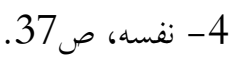

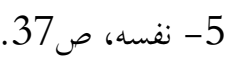

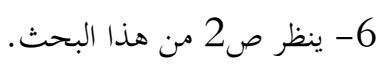


(( المغالطة التي تقع فيها عندما نحاول أن نبرهن على حقيقة قضية بالقضية نفسها ()) (1) بمعنى أننا نصدر ما يجب أن نبرهن عليه إلى المقدمات، وبذلك تكون النتيجة تحصيل حاصل على نهو صريح أو على نهو ضمني في المقدمات، والمثال عليه هو: كل إنسان بشر، وكل بشر ضَحّاك،

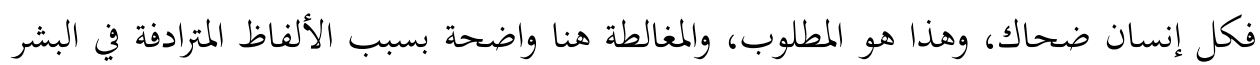
وإنسان، فالمقدمة الكبرى والنتيجة شيء واحد. السادس: أخذ ما ليس بعلة للنتيجة على أنه علة لها والعلة كما هو معروف هي ما فا ها

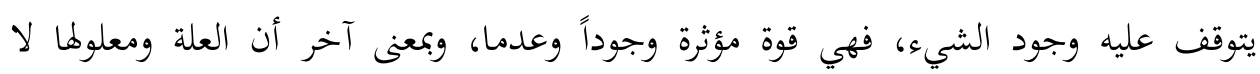

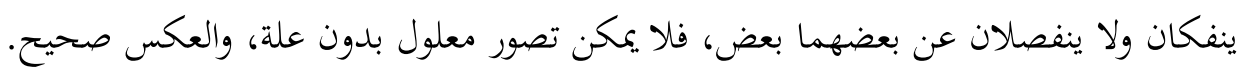

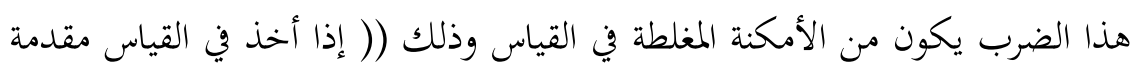
ما تلزم عنها نتيجة كاذبة، فأوهم الآخذ أن النتيجة إنما لزمت عن تلك المقدمة )( (2)، وهذا كثيرا ما يعرض في القياس السائق إلى المحال وهو ما ينتج الكذب والاستحالة، والقول الوخيم، والمثنال عليه هو ما يعرضه أرسطو، وهو، قول القائل: إنه ليس النفس والحياة شيئاً واحداً، ثم الفاعل

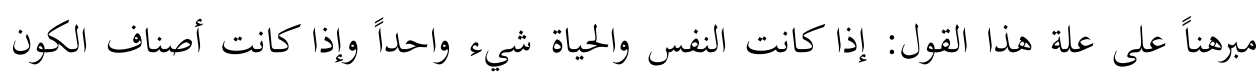

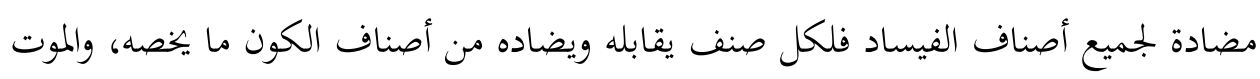

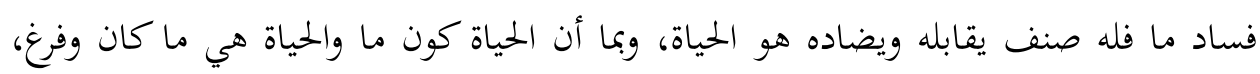

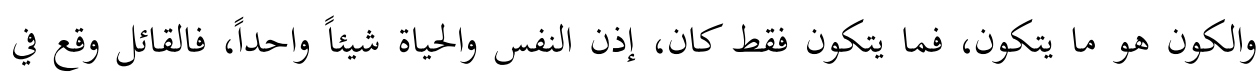
الخطأ في تعليله، فإذا لم يبلغ مقصده من إنتاج ما قصد، وكان مقصده أن يثبت: أن الحياة والنفس ليستا شيئاً واحداً، فكان تعليله بالكون والعدم، وهما ليستا بعلة وذلك فإن دل إلى الكون

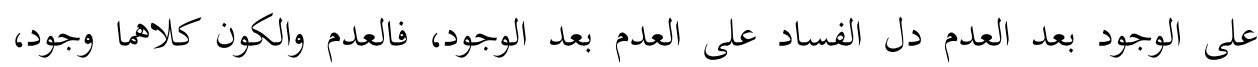
وكذلك الحياة كون فهي وجود والنفس أيضاً كون فهي وجود، وإذا جرينا القائل في برهانه يكون قوله الوجود غير موجود، وهذا ضرب من القول الوخيم والتبكيتات المضلة.

1- د. نُمَّمَ أحمد السرياقوسي، التعريف بالمنطق الصوري، ص391.

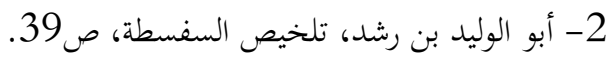


السابع: التغليط الذي يعرض من قبل أخذ المسائل الكثيرة مسألة واحدة، أي تكون

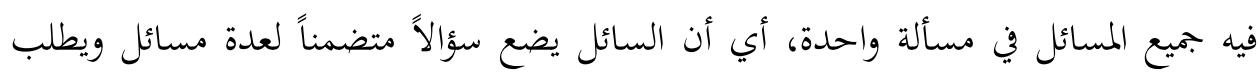

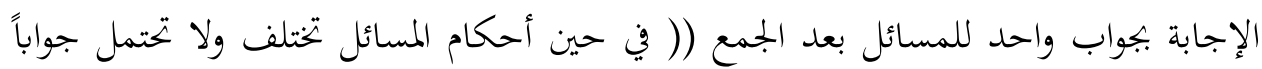

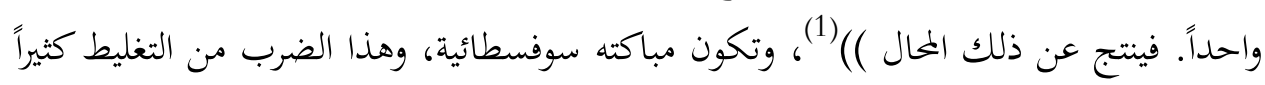

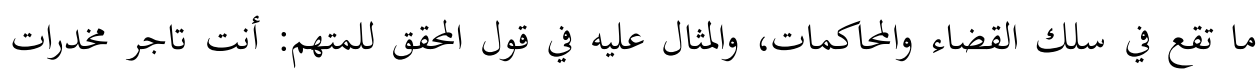

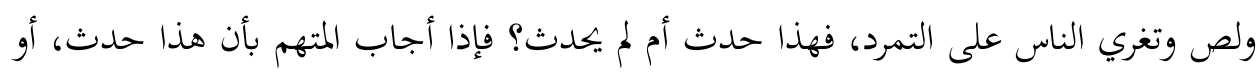

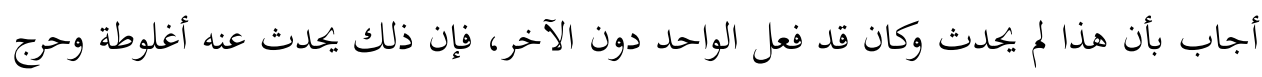
لمتهم، من خوف الزيادة في العقوبة.

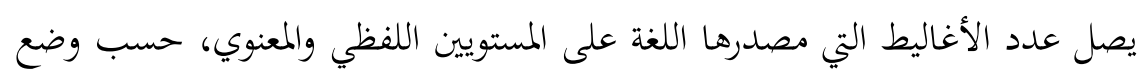

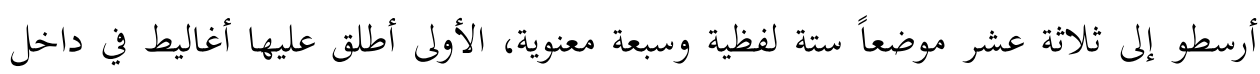

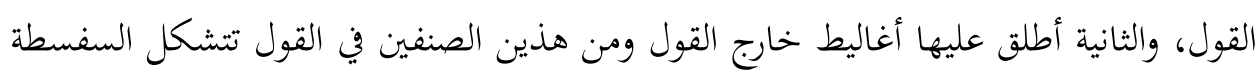

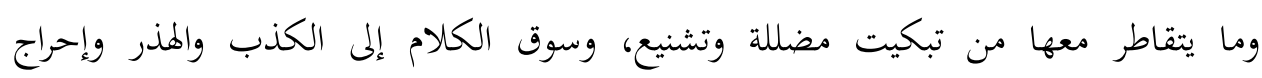

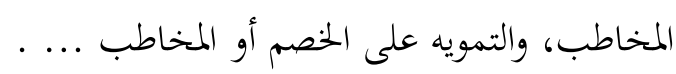

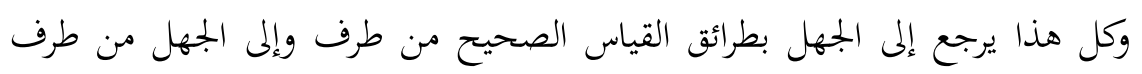
آخر باللغة و بألفاظها ودلالة معانيها وصورة تركيبها وقواعدها العامة.

1- د. جعفر آل ياسين، المنطق السنوي، ص131. 


\section{خاتمة:}

نصل إلى أن ظاهر السفسطة لم تكن ظاهرة برزت فجأة في بلاد اليونان، بل مهدت

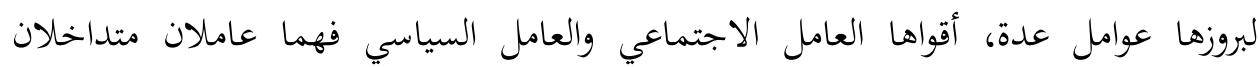
ومتكاملان، لا ينفك أحدهما عن الآخر أثراً و تأثيراً.

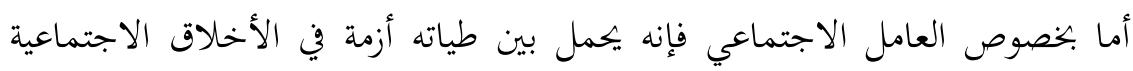
وذلك بسبب ما تركته الحروب الميدية في أواخر القرن الخامس ق.م بين الفرس واليونان من بـ خسارة في الممتلكات والأرواح انعكس على حالة الأفراد اقتصادياً ونفسياً، فبدأ المواطن اليوناني شغوفاً بامتلاك أكبر قدر من المال والثروة بأي طريقة كانت: وهذا لن يتسنى إلا برفض الأخلاقيات والشك في كل القيم ونبذها. أما العامل السياسي تمثل في نجاح الشعب في صراعه مع طبقة النبلاء، التي كانت لها سيادة البلاد، إلى جانب إصلاحات بيركلس (ت. 429 ق.م) الدستورية، فكانت الديمقراطية التي أتاحت الحرية على مختلف أبعادها للشعب اليوناني وأصبح كل مواطن في اليونان مالكاً لحرية

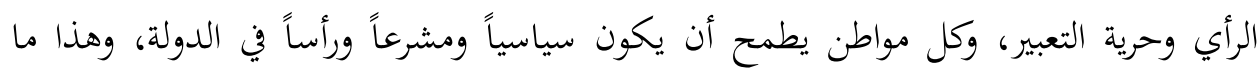

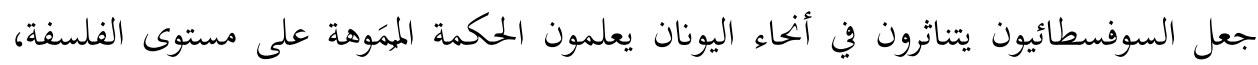
والتبكيتات المضللة على مستوى المنطق. 


\section{نتائج البحث:}

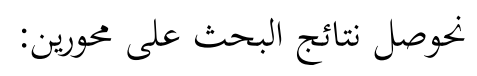

الأول: المحور المعرفي، سيادة الروح الفردية وتغلغلها في كل مناحي الحياة الاجتماعية

والسياسية والاقتصادية، بفضل تفشي الديمقراطية وتفكك قيمة رابطة الدم، وبهذا أصبح الفرد

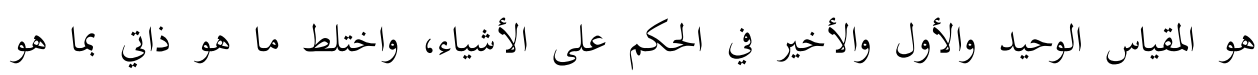
موضوعي، أي ما يجب أن يكون في محل الموضوع فرضي بهذا الخلط، وأن يكون في محل ما هو ذاتي، فلا وجود لحقائق ثابتة ومطلقة، بل ما هو موجود متغير والحقائق نسبية، وأنالحقيقة كما يراها الواحد لا كما يراها الآخرون. الثاني: المحور النفسي أو السيكولوجي: فيه يظهر السوفسطي أو المشاغبي، بصورة الأناني المغرور بالتفوق والغلبة، والمالك الوحيد للحقيقة، فالحق ما يراه هو لا ما يراه الآخرون.

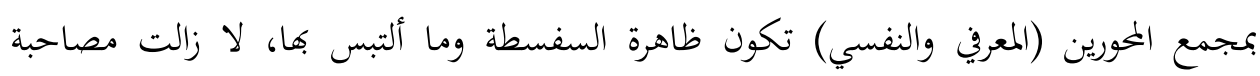

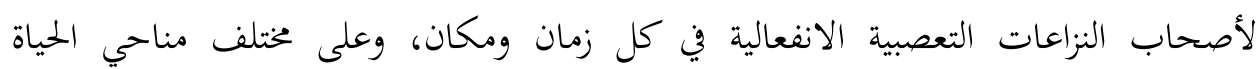
ومستوياتا. إها الفوضى الفكرية التي تبرز صورةا فيما هو حسي سُلوكي. 


\section{المصادر والمراجع}

1- أرسطو طاليس، الخطابة، تحقيق عبدالرحمن بدوي، دار القلم- بيروت 1979. 2- إمام عبدالفتاح إمام، محاضرات في المنطق، دار الثقافة للنشر - القاهرة 1992. 3- جفر آل ياسين، المنطق السينوي، دار الآفاق الجديدة - بيروت، ط لـ 1983.

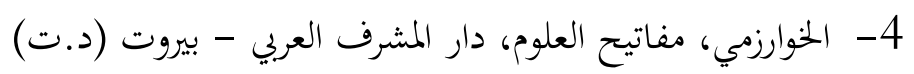
5- ابن رشد، تلخيص منطق أرسطو، طوبيقي وسوفسطيقي ( بجلد 6، 7) تحقيق، د. جيرار جهامي، دار الفكر اللبناني - بيروت، ط، أولى 1992.

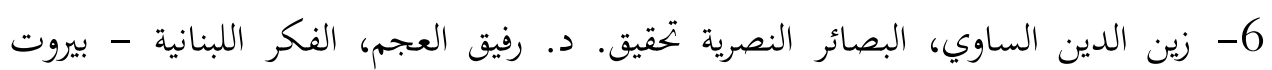
ط 1993 7- طه حسين، نظام الاثنين،دار المعارف - مصر 1963. 8- عبدالرحمن بدوعة المنطق الصوري والرياضي، وكالة المطبوعات - الكويت، ط الخامسة لامبن .1981

9- عبدالرحمن بدوي، منطق أرسط ( 3 أجزاء) تحقيق، دار القلم - بيروت 1980.

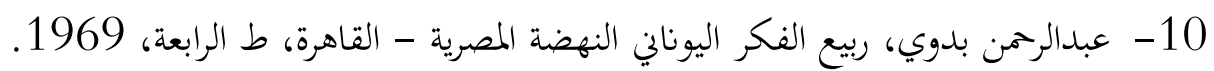

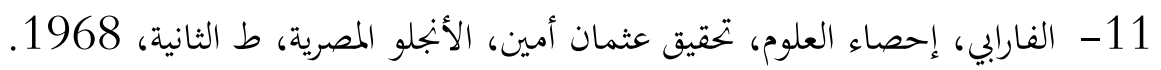
12- أبو الوليد بن رشد، تلخيص السفسطة،تحقق مُحَّم سليم، دار الكتاب - القاهرة 1972. 13- عُمَّد أحمد السرياقوسي، التعريف بالمنطق الصوري، دار الثقافة - القاهرة (د.ت).

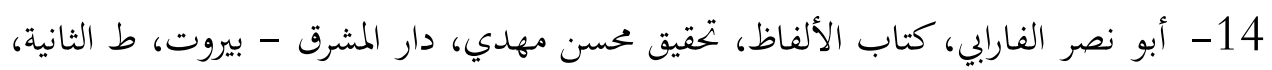
(د) (15) 15- يوسف الصديق، المفاهيم والألفاظ، الدار العربية للكتاب - ليبيا، تونس، ط الثانية، .د.) 